\title{
Autonomía estratégica bajo el prisma de la Estrategia Global Europea: directrices de su marco regulatorio
}

\author{
Strategic Autonomy under the Prism of the European Global Strategy: \\ Guidelines for its Regulatory Framework
}

María José Molina García ${ }^{1}$ y Miguel Ángel Benedicto Solsona ${ }^{2}$

Sumario: I. Reflexiones preliminares: contextualización del entorno geopolítico.-II. La autonomía estratégica en el contexto de la Estrategia Global. 1. Qué entendemos por autonomía estratégica. 2. Cuál es el propósito de la Estrategia Global.-III. Cobertura legal de la Acción Exterior Europea y de la Estrategia Global. 1. Multilateralismo y Derecho Internacional Público. 2. Fundamentos y marco normativo de la Acción Exterior Europea.-IV. Últimos avances en el desarrollo de la autonomía estratégica. 1. Cláusula de asistencia mutua. 2. Cooperación Estructurada Permanente. 3. Otras herramientas.-V. Consideraciones finales.-VI. Bibliografía.

Resumen: El desafiante contexto geopolítico internacional y el marco primario de la Acción Exterior de la Unión Europea (en su dimensión política, jurídica e institucional) proyectan la gestación y desarrollo de la Estrategia Global sobre Política Exterior y de Seguridad, y la ambición de autonomía estratégica como respaldo para la paz y un mundo más seguro. Interesa estudiar, desde una visión compartida y de acción común, cuál es el mandato de esta Estrategia para deducir si esta táctica operativa y estratégica se erige y se consolida con parámetros lícitos. Es decir, en un orden mundial basado en normas y en el multilateralismo, ¿se están adoptando las medidas propias de un entorno regulatorio de respeto y promoción de los derechos humanos, libertades fundamentales y Estado de Derecho (artículo 3.5 del TUE)?

${ }^{1}$ María José Molina García es Profesora acreditada contratada Doctor y Responsable de Programas en el Centro de Estudios Garrigues. E-mail: mjosemolinagarcia@gmail.com

2 Miguel Ángel Benedicto Solsona es Doctor, Profesor adjunto en Universidad Europea de Madrid y Profesor Asociado en Universidad Complutense de Madrid. E-mail: miguel.benedictosolsona@gmail.com 
Palabras claves: Autonomía estratégica, Derecho europeo, Estrategia Global Sobre Política Exterior y de Seguridad Común, Geopolítica internacional, Unión Europea.

Abstract: The challenging international geopolitical context and the primary framework of the European Union's External Action (in its political, legal and institutional dimension) points to the emergence and development of the Global Strategy on Foreign and Security Policy, and the ambition of strategic autonomy as support for peace and a safer world. It is interesting to study, from a shared vision and common action, what the mandate of this Strategy is in order to deduce whether this operational and strategic perspective is being built and consolidated with legal parameters. That is, in a world order based on norms and multilateralism, are the measures of a regulatory environment of respect and promotion of human rights, fundamental freedoms and the rule of law (Article 3.5 of the TEU) being adopted?

Keywords: Strategic autonomy, European Law, Global Strategy on Foreign and Security Policy, International geopolitics, European Union

\section{Reflexiones preliminares: contextualización del entorno geopolítico}

La Unión Europea (en adelante UE) no es ajena a la creciente inestabilidad que acontece en su entorno geopolítico, en profunda y vertiginosa transformación, emergiendo nuevas amenazas y desafíos que la obligan a intensificar y dar un nuevo impulso a la cooperación (bilateral y multilateral) y, por ende, al marco regulatorio en materia de seguridad y defensa, tal y como sentenciaron los máximos dirigentes europeos en la cumbre de Bratislava de septiembre de 2016 ${ }^{3}$. Desde el Sahel hasta el Cuerno de África ${ }^{4}$, pasando por Oriente Próximo hasta el Cáucaso, los nuevos conflictos en Europa del Este, el fracaso de la primavera árabe, las guerras ininterrumpidas en Siria e Iraq, los flujos de refugiados hacia Europa, la intensificación del terrorismo en los Estados centrales de la Unión, la creciente auto-deses-

${ }^{3}$ En cumplimiento de este compromiso véase las conclusiones que formularon los dirigentes europeos en diciembre de 2016. Una síntesis de las mismas puede consultarse en https://www.consilium.europa.eu/es/policies/defence-security/, acceso el 2 de septiembre de 2019.

${ }^{4}$ Para conocer en detalle la política de la UE hacia el Norte de África y el Sahel, tanto en términos geográficos como en términos estratégicos de acuerdo con lo expuesto en la nueva Estrategia Global Europea véase David García Cantalapiedra y Raquel Barras, «El Norte de África y el Sahel y la Estrategia Global de Seguridad de la Unión Europea», UNISCI Journal, n. ${ }^{\circ} 42$ (2016): 173-196. 
tabilización en Turquía, las tensiones con China, la proliferación de armas de destrucción masiva (el programa nuclear iraní), el cambio climático, la inseguridad energética, la volatilidad económica... acentúan la gravedad del inseguro contexto internacional y evidencian la flaqueza de los instrumentos legales y, a su vez, la necesidad de contar con ellos para proporcionar un entorno estable y seguro 5 .

Se leía en un comunicado del Consejo Europeo de diciembre de 2016 que «los Estados europeos deben tomar mayor responsabilidad de su seguridad», pues en palabras de la entonces Alta Representante de la UE, Federica Mogherini, «es un momento histórico para la defensa europea» ${ }^{6}$. Por su parte, el Presidente de la Comisión Europea, Jean-Claude Juncker, afirmaba en su discurso sobre el Estado de la Unión de 2017 que «para 2025 necesitamos una auténtica Unión Europea de Defensa»7; y la canciller alemana, Angela Merkel, anunciaba en la cumbre del G7 en Taormina (Italia - mayo de 2017), que «los europeos tenemos que tomar el destino en nuestras manos». Para avanzar en esa línea, como declaró el actual Presidente del Consejo Europeo, Donald Tusk, en la reunión informal del Consejo Europeo en Sibiu el 9 de mayo de 2019, es indispensable gestionar los asuntos internos y afrontar los desafíos mundiales «teniendo en cuenta que el mundo que nos rodea es cada vez más cambiante e impredecible». Y en esta tendencia de posicionamiento europeo se inspira la comunicación que como contribución a la agenda estratégica 2019-2024 formuló la Comisión con un título

5 El Derecho debe ser, como observa Rovira, «estable y evolutivo», ya que la seguridad tiene también la finalidad de reconocer situaciones cambiantes (M. ${ }^{\text {a }}$ Carolina Rovira Flórez de Quiñones, «Seguridad y Estado de Derecho», Anales de la Cátedra Francisco Suárez, 11-1 (1971): 74). La estabilidad debe buscarse en cuanto al ordenamiento jurídico se refiere y no en relación con las normas, pues éstas, por su propia naturaleza, deben ser variables.

6 «Dos corrientes han dominado el debate en el ámbito de la defensa europea. Una podría denominarse maximalista-melancólica, formada por aquellos que ven obvio el objetivo político común de una Unión de la defensa, olvidando quizá tanto la diversidad de intereses industriales, económicos, políticos involucrados, como los recelos estratégicos propios de los países participantes. La otra podría denominarse inmovilista-cínico-realista, y recuerda que pocas cooperaciones militares son exitosas y que exaltaciones públicas de "“ahora sí" se han producido desde Bruselas en el pasado en el área de defensa con escasos resultados. Si los primeros minusvaloran las dificultades, los segundos añoran una gran némesis compartida como única vía para superar los intereses individuales. Puesto que ambos pensamientos conviven con la dificultad de cooperar militarmente, merece la pena reflexionar sobre las razones que hacen de la defensa un área en la que es tan complicado establecer alianzas duraderas...»véase Bernardo Navazo, «Una tercera vía hacia la defensa europea», Política Exterior, Vol. 32, n. ${ }^{\circ} 182$ (marzo-abril 2018): 120-125.

7 Véase texto completo del discurso sobre el estado de la Unión 2017, acceso el 10 de julio de 2019, en http://europa.eu/rapid/press-release_SPEECH-17-3165_es.htm 
muy ilustrativo «preparación para una Unión más unida, más fuerte y más democrática en un mundo sumido en una incertidumbre creciente» ${ }^{8}$.

En el marco de estas pinceladas y teniendo como telón de fondo la Acción Exterior de la Unión (en su dimensión política, jurídica e institucional) y el propio orden (o desorden) internacional, se exigió revisar la Estrategia Europea de Seguridad adoptada en $2003^{9}$ y que se orientaba, junto con el Informe sobre su aplicación de diciembre de 2008, a ofrecer seguridad en un mundo en evolución y representar la dimensión exterior de la seguridad europea. Es por ello que el Consejo Europeo solicitó en junio de 2015 a la Alta representante y Vicepresidenta de la Comisión, Federica Mogherini, la elaboración de una Estrategia Global sobre Política Exterior y de Seguridad de la UE (EUGS en sus siglas en inglés) ${ }^{10}$. Finalmente, la Alta Representante presentó a los máximos dirigentes políticos una estrategia de seguridad largamente esperada, «Visión compartida, acción común: una Europa más fuerte». La misma se adoptó en la Cumbre Europea celebrada los días 28 y 29 de junio de 2016, justo después del Brexit ${ }^{11}$, lo que generó que

${ }^{8}$ La agenda estratégica 2019-2024 aprobada por el Consejo Europeo marca como prioridad «promover los intereses y los valores de Europa en el mundo y para ello actuar con mayor determinación y efectividad a la hora de ejercer nuestra influencia, dando una prioridad más clara a nuestros intereses y aprovechando todas las políticas con ese propósito». Esto constituye el primer marco político para emprender en el nuevo ciclo institucional una reforma de calado, sobre una doble base: (1) aumentar el peso del Alto Representante como Vicepresidente de la Comisión; y (2) mejorar el funcionamiento de la PESC. Consúltese texto completo de la Comunicación, acceso el 15 de junio de 2019, en https://ec.europa.eu/transparency/regdoc/rep/1/2019/ES/COM-2019-218-F1-ES-MAIN-PART-1.PDF, siendo la contribución de la Comisión Europea a la reunión informal de los dirigentes de la EU-27 en Sibiu (Rumanía) el 9 de mayo de 2019.

9 Texto adoptado por el Consejo Europeo celebrado los días 12 y 13 de diciembre del 2003, cuya elaboración fue coordinada por Javier Solana [acceso el 5 de junio de 2019, https://www.consilium.europa.eu/media/30808/qc7809568esc.pdf]. Y en el documento Estrategia Europea de Seguridad. Una Europa segura en un mundo mejor se pude consultar el informe sobre la aplicación de dicha Estrategia, [acceso el 5 de junio de 2019, https://www. consilium.europa.eu/media/30808/qc7809568esc.pdf].

${ }_{10} \mathrm{Al}$ respecto véase el documento oficial «Una visión común, una actuación conjunta: una Europa más fuerte. Estrategia global para la política exterior y de seguridad de la Unión Europea» (2016). Se trata de un documento de 60 páginas que está estructurado en torno a cuatro apartados: (a) una Estrategia global para promover los intereses de los ciudadanos; (b) Principios rectores de nuestra Acción Exterior; (c) las prioridades de nuestra Acción Exterior; (d) de la visión a la acción. Texto completo disponible en https://europa.eu/globalstrategy/sites/globalstrategy/files/eugs_es_version.pdf, acceso el 12 de julio de 2019. Asimismo, una información detallada de dicha Estrategia Global y el balance de su primer año de implantación puede consultarse en el siguiente enlace web http://europa.eu/globalstrategy/en, acceso el 10 de septiembre de 2019.

${ }^{11}$ La salida del Reino Unido de la Unión Europea, comúnmente abreviada como brexit (acrónimo de las palabras inglesas Britain y exit). 
fuese acogida - inicialmente- con frialdad por los Jefes de Estado y de Gobierno de entonces.

El contexto que inspiró la EUGS fue, como mejor punto de partida, el reconocimiento propio de una crisis de identidad que estaba debilitando la credibilidad del sistema dentro y fuera de la UE. Inmersos en ese entorno un tanto marchitado, ¿cómo iba a ser posible labrar esa visión compartida y acción conjunta? Federica Mogherini decidió seguir con el cronograma estipulado, fundamentándolo en los siguientes términos: «En tiempos difíciles, una Unión fuerte es aquella que piensa de manera estratégica, la que comparte una visión y actúa conjuntamente. Y esto es aún más cierto tras el referéndum británico». Bajo el paraguas de este planteamiento se trazan las prioridades de lo que será la nueva Estrategia, perfilándose oficialmente sobre los siguientes postulados: la seguridad propia de la UE y de sus Estados vecinos; el cómo afrontar los conflictos y episodios de crisis; la atención a los órdenes regionales de cooperación en todo el mundo; y la vocación de propulsar una gobernanza mundial eficaz y más acorde con la realidad internacional. Estas premisas infundieron el concepto de «pragmatismo basado en principios», extraído literalmente de la EUGS. Se trata de un enfoque que, como se desprende expresamente del Proyecto Europa 2030, llama a «la unidad de la propia UE y de sus Estados miembros, a la gestión de los desafíos de un mundo cada vez más interdependiente, a la actuación responsable y compartida a nivel mundial y a una asociación selectiva como base para ejercer un papel relevante como actor principal a nivel global» ${ }^{12}$. Frente a los retos que hoy día debe afrontar Europa, el Proyecto aludido en líneas precedentes es un ingrediente proactivo que aspira a legitimar la supervivencia de la UE en una coyuntura geopolítica compleja, reafirmarla como actor relevante en el vecindario más próximo y también a nivel mundial, y proyectarla como factible proveedor de seguridad global.

La teoría así formulada pinta bien, pero es preciso determinar si su implementación práctica a través de diversos medios (políticos, legales, presupuestarios de recursos civiles y militares), está siendo adecuada y cuál es el logro de resultados. Para tratar de esclarecer estas cuestiones que se enuncian y abordar este planteamiento, se aspira a formular el concepto de autonomía estratégica desde los parámetros extraídos de la EUGS para adentrarnos posteriormente en el marco regulatorio que la sustenta y la dota de legitimidad. De este modo, nuestro empeño es, desde un enfoque analítico, estimar si la UE puede lograr una mayor y sólida autonomía estratégica en virtud del sostén jurídico con el que hoy día cuenta, pues el marco regulato-

12 Véase Informe al Consejo Europeo del Grupo de Reflexión sobre el futuro de la UE en 2030, «Proyecto Europa 2030. Retos y oportunidades» (Mayo 2010). Documento disponible en https://www.consilium.europa.eu/media/30761/qc3210249esc.pdf, acceso el 12 julio de 2019. 
rio otorga legitimidad para llevar a cabo prioridades políticas y actuaciones concretas (tanto legislativas como no legislativas) en el oportuno ámbito de la Estrategia Global. Esto es, ¿puede la UE progresar hacia un mayor grado de autonomía sirviéndose de la amplia gama de instrumentos (legales, políticos, económico-financieros y militares) que se van a poner a su disposición?

La evocación por ser más autónomos imprime el tenor literal de la Estrategia, definiéndose que su objetivo sea facilitar un amplio marco estratégico y operativo, que permita a la Unión entender y afrontar de modo lícito, firme y coherente los actuales desafíos regionales e internacionales. Con la entrada en vigor del Tratado de Lisboa en 2009, en el marco de las disposiciones generales de la Acción Exterior, se impulsó la puesta en marcha de la Política Exterior y de Seguridad Común (PESC) y como parte integral de la misma, la Política Común de Seguridad y Defensa (PCSD) ${ }^{13}$, pero como se evaluará más adelante no ha sido hasta hace poco más de cuatro años cuando aquellas herramientas han comenzado a implementarse verdaderamente, y la EUGS deviene en un buen acicate para ello. El estallido de la crisis económica en torno a 2008-2012 y la situación política de los países del Este provocaron un cierto estancamiento en las expectativas y el progreso en este tipo de iniciativas. No obstante, un paso adelante en esta línea de actuación europea viene representado por el hecho de promoverse que en casi todas las reuniones de Jefes de Estado y de Gobierno europeos se dedique algún apartado en la agenda a la seguridad y defensa, y el impulso de la EUGS ha contribuido favorablemente a ello.

En efecto, está inclusión en el orden del día es un importante avance, pero no por ello suficiente dado que estamos en un campo de actuación vivo, flotante y enmarañado, pues tal y como se manifestó en la Declaración oficial efectuada con motivo de la celebración en Roma del 60 aniversario de los Tratados constitutivos ${ }^{14}$, «la Unión Europea se enfrenta a retos sin precedentes, tanto mundiales como interiores: conflictos regionales, terrorismo, presiones migratorias crecientes, proteccionismo, desigualdades sociales y económicas». Los ataques terroristas del ISIS en territorio europeo, la amenaza de Rusia en la vecindad Este-europea, el reto de los refugiados, la Administración Trump y el Brexit, han sido últimamente los principales catalizadores

${ }^{13}$ La política común de seguridad y defensa (PCSD) forma parte integral de la política exterior y de seguridad común (PESC) de la Unión. Véase el título V (Disposiciones generales relativas a la Acción Exterior de la Unión y disposiciones específicas relativas a la política exterior y de seguridad común) del Tratado de la Unión Europea.

${ }^{14}$ El 25 de marzo de 2017, los Jefes de Estado o de Gobierno de la UE se han reunido en Roma (Italia) con motivo del $60 .^{\circ}$ aniversario de los Tratados de Roma. Este magno encuentro ha constituido una ocasión para reflexionar sobre el estado de la Unión Europea y mirar hacia el futuro del proceso de integración. 
de las actuaciones en materia de seguridad y defensa. Y es poco probable que esta situación cambie en un futuro muy próximo. En cualquier caso, las enrevesadas circunstancias que atraviesa la integración europea complican esbozar el corpus político-jurídico y la actualización de lo que debería ser la PESC en sus distintos ámbitos de actuación y, por ende, de la EUGS. Sin obviar, que la reflexión sobre las próximas aspiraciones (intereses y objetivos) de la UE está supeditada a los resultados extraídos de las últimas elecciones al Parlamento europeo (mayo de 2019), que inauguran un nuevo ciclo legislativo e institucional junto con una renovada dirección y/o liderazgo político al frente de la Acción Exterior ${ }^{15}$. Por tanto, la legislatura 2019-2024 que recién se ha iniciado, ¿traerá un aumento exponencial de la autonomía estratégica y de las aspiraciones de la EUGS?

\section{La autonomía estratégica en el marco de la Estrategia Global}

\section{Qué entendemos por autonomía estratégica}

En su prólogo, la nueva estrategia expone la ambición de conseguir «una autonomía estratégica para la Unión Europea» y de contar «con la fuerza para contribuir a la paz y la seguridad en la región y en todo el mundo» ${ }^{16}$. En un intento de anticipar futuros desarrollos en este ámbito, el Consejo Europeo emitió un informe en el año 2010 sobre las perspectivas de Europa para el 2030, destacándose la necesidad de que «los Estados miembros de la UE reconozcan que la seguridad interior está supe-

${ }^{15}$ La Alta Representante (AR) actual es Federica Mogherini. Su mandato finalizó el 31 de octubre de 2019. En el Consejo Europeo extraordinario concluido el 2 de julio de 2019 se designó a Josep Borrell como futuro Alto Representante y Vicepresidente (artículo 18 del TUE). Posteriormente, el 6 de agosto, el Consejo Europeo nombró a Josep Borrell como AR. En su condición de vicepresidente de la Comisión, se sujeta al voto de aprobación del Parlamento Europeo. Dicha designación ha sido respaldada por el Parlamento Europeo. Consecuentemente, a partir del 1 de noviembre de 2019 Josep Borrell ocupará el cargo anteriormente citado. El AR, nombrado para un periodo de cinco años, dirige la Política Exterior y de Seguridad Común, incluyendo la Política de Seguridad y Defensa Común, preside el Consejo de Asuntos Exteriores y es uno de los vicepresidentes de la Comisión Europea. El AR asegura la coherencia de la Acción Exterior de la UE, es responsable dentro de la Comisión de responsabilidades que incumben a la misma en materia de relaciones exteriores y de la coordinación de otros aspectos de la Acción Exterior de la UE. Para el desempeño de sus funciones, el AR cuenta con la ayuda del Servicio Europeo de Acción Exterior. Dicho servicio colabora con los servicios diplomáticos de los países de la UE. Está compuesto por funcionarios y agentes de la UE, así como por personal delegado de los servicios diplomáticos nacionales.

16 Servicio Europeo de Acción Exterior (2016): 3-4. 
ditada en gran medida a la consecución de un entorno exterior seguro» ${ }^{17}$. Con posterioridad, en marzo de 2017, poco antes del $60 .^{\circ}$ aniversario de los Tratados de Roma, la Comisión publicó su Libro Blanco sobre el futuro de Europa ${ }^{18}$. En el mismo se esbozaron cinco posibles escenarios para el futuro de una Unión de veintisiete Estados miembros y es sintomático que en ellos se planteasen cuestiones de base sobre los objetivos europeos, como son el tratamiento en profundidad de las cuestiones concernientes a seguridad y defensa. Este fue el punto de partida de un amplio debate sobre el futuro de Europa, que inspiró la agenda estratégica 2014-2019 e inculca en la actualidad las principales prioridades políticas, legales, operativas... de la próxima agenda. Se teje el 9 de mayo de 2019, en la reunión que los líderes europeos mantuvieron en Sibiu, la agenda estratégica 2019-2024, abordándose las oportunidades, prioridades y desafíos como mejor orientación para los próximos trabajos que la Unión acometerá. En opinión de la Comisión, las acciones futuras deben vertebrarse en torno a cinco dimensiones: protectora, competitiva, equitativa, sostenible e influyente. Y, en el ámbito de este último encuentro se aspiró a culminar la renovación del compromiso de una Unión que sea capaz de dar respuestas a las cuestiones que realmente importan a los ciudadanos. Veremos si se conquista esta voluntad.

La Estrategia Solana de 2003 había quedado obsoleta ante las nuevas amenazas y retos que se cernían sobre Europa, decidiéndose una nueva Estrategia Global para la seguridad interna y externa que priorizase ${ }^{19}$, según se ha reseñado anteriormente, el terrorismo, las amenazas híbridas y territoriales, la ciberseguridad, el cambio climático, la volatilidad económica, la inseguridad energética, la inmigración ilegal, etc. Al respecto, afirmamos que, en el entorno de inestabilidad e incertidumbre en que nos encontramos y dada la confluencia de políticas internas y externas, la Unión debe actuar de forma coordinada y coherente para garantizar sus principios, sus valores e intereses en tiempos de cambio. Es por ello que adquiere sentido el enfoque integrado adoptado por la EUGS, definido en 2016, y que enfatiza llevar a cabo acciones de prevención, gestión y resolución de conflictos, a diferencia de la anterior Estrategia de Seguridad que hacía hincapié solo en la prevención de conflictos.

17 Proyecto Europea 2030. Retos y Oportunidades. Informe al Consejo Europeo del Grupo de Reflexión sobre el futuro de la UE en 2030 [acceso el 5 de septiembre de 2019, https://www.consilium.europa.eu/media/30761/qc3210249esc.pdf].

18 Documento completo disponible en https://ec.europa.eu/commission/sites/beta-political/files/white_paper_on_the_future_of_europe_en.pdf, acceso el 10 de septiembre de 2019.

19 A Global Strategy for the European Union's Foreign and Security Policy. [acceso el 4 de junio de 2019, https://europa.eu/globalstrategy/sites/globalstrategy/files/eugs_review_web.pdf]. 
La Estrategia se califica como global, no sólo porque identifica el mundo como único escenario sino por las herramientas que pretende emplear; y aunque alude a la autonomía estratégica de la UE, no la define. Podría ser la necesidad de que Europa pueda defenderse de agresiones de terceros sin tener que depender de la OTAN. Sin embargo, el concepto de autonomía estratégica es distinto, según el autor que se consulte, extrayéndose diversas acepciones o una semántica distinta en base a los deseos o intereses en juego, como acertadamente señala HOWORTH ${ }^{20}$. No es solo el tratamiento teórico o práctico que se le dé al termino por la doctrina de autor, sino también cómo es abordado individualmente o de forma particular por cada Estado miembro ${ }^{21}$. Para unos es la creación de una industria europea de defensa en términos de suministro de capacidades militares para los Estados Miembros ${ }^{22}$; para otros, la capacidad de emprender operaciones militares exigentes en la vecindad europe $\mathrm{a}^{23}$ o las capacidades militares indispensables para llevar a cabo acciones autónomas por un actor estratégico ${ }^{24}$. En efecto, la autonomía estratégica «no tiene que ser un concepto único, intuitivo ni imparcial» ${ }^{25}$ y cuenta con tres componentes esenciales: el político (estratégico), el operativo (que depende de las capacidades) y el industrial (relacionado con los equipos) ${ }^{26}$. Todos estos ingredientes tienen que encontrar amparo en el debido marco regulatorio para, consecuentemente, dotar de legitimidad cualquier intervención o actuación europea en el ámbito de la EUGS.

Para conquistar unidad, en un marco de gestión interdependiente, de responsabilidad compartida y con espíritu asociativo, la autonomía estratégica viene a ser un segmento vital en el proceso de fortalecimiento de la

20 Jolyon Howorth, «Autonomy and Strategy: what should Europe want?», Security Policy Brief, n. ${ }^{\circ}$ 110, (April 2019), acceso el 22 de julio de 2019, http://www.egmontinstitute. be/content/uploads/2019/04/SPB110.pdf?type=pdf

${ }^{21}$ Siguiendo a Félix Artega, «sólo algunos países, los grandes, disponen de criterios propios de autonomía estratégica que puedan aplicar a la UE [...]». Las referencias que describen son Francia, Alemania, Italia, España (Félix Arteaga, «La autonomía estratégica y la defensa de europea», ARI 76 (2017): 3-5.

22 Tony Lawerence, Henrik Praks \& Pauli Järvenpää, Pauli, «Building Capacity for the EU Global Strategy. International Centre for Defence and Security», Policy Paper (June 2017). RKK, International Centre for Defence and Security.

${ }^{23}$ Gergely Varga, «Towards European Strategic Autonomy? Evaluating the New CSDP Initiatives», KKI Studies, T-2017/7, Institute for Foreign Affairs and Trade.

${ }^{24}$ Félix Arteaga, «El Nuevo Concepto Estratégico de la OTAN: lógica y estructura», Real Instituto Elcano (2010).

${ }^{25}$ Félix Arteaga, «La autonomía estratégica y la defensa de europea», ARI 76 (2017), acceso el 20 de julio de 2019, en http://www.realinstitutoelcano.org/wps/portal/rielcano_es/ contenido?WCM_GLOBAL_CONTEXT=/elcano/elcano_es/zonas_es/ari76-2017-arteagaautonomia-estrategica-defensa-europea

26 Ibídem. 
UE. La introducción de este concepto de «autonomía estratégica» es fundamental, refleja la evolución de los debates en el seno de la Unión y la voluntad de avanzar en materia de defensa, para «garantizar la seguridad dentro y fuera de sus fronteras» ${ }^{27}$. Es más, es un viejo objetivo de la defensa europea $^{28}$ y no una propuesta originaria de hoy día. Tal y como se reconoce en el documento oficial de la EUGS, es la intención de adquirir una capacidad propia en materia de defensa y contribuir a la seguridad colectiva. De este modo se manifiesta la necesidad de «asumir una mayor responsabilidad en nuestra seguridad», pues contar con «un nivel adecuado de ambición y autonomía estratégica es importante para la capacidad de Europa de fomentar la paz y garantizar la seguridad dentro y fuera de sus fronteras» ${ }^{29}, \mathrm{y}$ esto requiere «un aumento del presupuesto para seguridad y defensa, mayores capacidades y cooperación, una estructura militar más unida, una sólida industria europea de defensa y voluntad política por parte de los Estados miembros ${ }^{30}$. Unido a una real diplomacia multilateral que pueda alumbrar soluciones sostenibles en el tiempo.

En este ansiado nivel de ambición, que es la autonomía estratégica europea, la Unión debe ser capaz de dispensar la debida protección y un entorno seguro, tanto desde un plano ad-intra como ad-extra, y eso pasa por responder de forma común a problemas dispares y acuciantes (terrorismo, amenazas híbridas, ciberseguridad, seguridad energética, delincuencia organizada, gestión de las fronteras exteriores, cambio climático...). Conforme a este alterado y bullicioso contexto geopolítico, cada vez más, los ciudadanos demandan a Europa protección dentro y fuera de sus límites fronterizos, dado que la magnitud de estos retos es tal que ningún Estado miembro puede abordarlos con éxito por sí solo. Ante todo estamos ante una responsabilidad común, más aún cuando la tradicional línea divisoria entre seguridad interna y externa está desdibujada. Conscientes de esta situación, los Estados miembros vuelven a invertir en defensa. En efecto, «en un mundo cada vez más inestable y en el que las amenazas transfronterizas para nuestra seguridad van en aumento, ningún país puede arreglárselas solo», según se explica en el comunicado emitido el 20 de febrero de 2019 por la Comisión Europea; «de ahí que la Comi-

27 Servicio Europeo Acción Exterior (2016): 14.

28 Arteaga, «La autonomía estratégica...».

${ }^{29}$ A Global Strategy for the European Union's Foreign and Security Policy [acceso el 15 de junio de 2019, https://europa.eu/globalstrategy/sites/globalstrategy/files/eugs_review_web.pdf].

${ }^{30}$ Miguel Ángel Benedicto Solsona, «Implicaciones de la estrategia global para la política exterior y de seguridad de la UE», Cuaderno de Estrategia. Una estrategia global de la Unión Europea para tiempos difíciles, n. ${ }^{\circ} 184$ (Febrero 2017), Instituto Español de Estudios Estratégicos, Ministerio de Defensa. 
sión Juncker esté realizando un esfuerzo sin precedentes por proteger y defender a los europeos», continúa el citado texto ${ }^{31}$.

Esta predisposición implica necesariamente compromisos tomados al más alto nivel por los Jefes de Estado y de Gobierno, como podría ser la constitución de un Consejo Europeo de Seguridad y Defensa que tenga carácter periódico. Del mismo modo, pasa por instaurarse un diálogo reforzado sobre las capacidades militares, esto es, un examen coordinado y anual de la defensa, que posibilite nuevas acciones de cooperación multilateral, para colmar las lagunas existentes en materia de capacidades de las operaciones militares europeas. Es por ello que estimulando la cooperación, la UE puede ayudar a maximizar los resultados y la calidad de la inversión de los Estados miembros en la defensa ${ }^{32}$. En este sentido, el Plan de Acción sobre movilidad militar dentro y fuera de la Unión Europea, presentado por la Comisión europea y la Alta Representante, con el propósito de alcanzar una auténtica Unión de Defensa a más tardar en 2025, señala en su hoja de ruta diversos ámbitos de actuación ${ }^{33}$, entre otros, los aspectos normativos y de procedimiento.

A la vista de los apuntes que se extraen del análisis formulado, la autonomía estratégica es la capacidad de actuación autónoma de la UE en cualquier conflicto interno o externo con sus propias capacidades civiles y militares y herramientas de seguridad y de defensa, sin necesidad de que intervenga la Alianza Atlántica (OTAN). Es decir, de la necesidad de que Europa pueda defenderse de agresiones de terceros sin tener que depender exclusivamente de la Alianza o de un aliado como es Estados Unidos con quien comparte intereses, pero con quien también rivaliza. La Unión tiene que asumir plenamente su responsabilidad en este ámbito. No obstante esta apreciación, no se debe descartar la cooperación y colaboración con

31 Véase Comunicado de prensa «Presupuesto de la UE para el período 2021-2027: la Comisión acoge con satisfacción el acuerdo provisional relativo al futuro Fondo Europeo de Defensa» [acceso el 5 de junio de 2019, http://europa.eu/rapid/press-release_IP-19-1269_es.htm].

32 Apoyar la cooperación en materia de defensa mediante las herramientas financieras. La Comisión desempeñará un papel activo con respecto a las herramientas financieras. Creará un comité ad hoc compuesto por los Estados miembros y las partes interesadas pertinentes, con el objetivo de estandarizar las herramientas financieras, en la medida de lo posible, a fin de permitir su rápido despliegue en el contexto de cada proyecto específico. Además, establecerá un grupo operativo que ayudará a los Estados miembros, cuando lo soliciten, a aplicar las herramientas financieras a proyectos colaborativos específicos de adquisición. De este modo, la Comisión hará una contribución concreta a la hora de apoyar a los Estados miembros en la realización de proyectos colaborativos de adquisición.

${ }^{33}$ Este plan de acción adoptado en marzo de 2018 se ha presentado a los Estados miembros de la Unión para su estudio y aprobación. Está previsto que las primeras acciones se lleven a cabo en los próximos meses. En el verano de 2019, a más tardar, se presentará a los Estados miembros un primer informe de situación sobre la ejecución de este plan de acción. 
la OTAN. Es más, es incuestionable el papel distinguido de la OTAN en la defensa colectiva, siendo vital buscar la cooperación entre ambas organizaciones internacionales. Aunque como decíamos, la EUGS no define la autonomía estratégica, pero el plan de implementación de la Estrategia Global si recoge este concepto ${ }^{34}$, que no es incompatible con la Alianza sino que, desde el punto de vista europeo, la refuerza.

\section{Cuál es el propósito de la Estrategia Global}

La EUGS apuesta, como se apuntaba en líneas precedentes, por un pragmatismo basado en principios en relación con el contexto en el que se enmarca Europa. Esto es, una realpolitik a la europea que renuncia a exportar el modelo de la Unión y con un importante cambio de filosofía respecto de la Estrategia de $2003^{35}$. Según se extrae del documento oficial, aboga por: (a) la seguridad (interior y exterior); (b) la resiliencia de los Estados y las sociedades de nuestros vecinos orientales y meridionales; (c) un enfoque integrado en relación con los conflictos, y con la prevención como elemento central; (d) órdenes regionales de cooperación; (e) gobernanza mundial para el siglo XXI. Por su enfoque global, la EUGS no deja de lado áreas lejanas, como por ejemplo Asia, pues aspira a convertirse en proveedor mundial de seguridad y recoge un planteamiento multidimensional e integral para resolver los conflictos con una miscelánea de poder duro y blando. Todo ello en un sistema mundial que debe estar articulado por normas, de respeto a los principios de la Carta de las Naciones Unidas y del Derecho Internacional.

Es en 2013 cuando el Consejo Europeo encomendó a Mogherini la revisión de la Estrategia de Seguridad de la Unión, y también es el momento de la publicación de un documento fundamental sobre el denominado concepto integral: «El enfoque integral adoptado por la UE en relación con los

${ }^{34}$ La autonomía estratégica de Europa implica la capacidad de actuar y cooperar con socios internacionales y regionales siempre que sea posible, al tiempo que puede operar de manera autónoma cuando y donde sea necesario. Esto se suma a la credibilidad de la UE con respecto a los socios. No hay contradicción entre los dos. Los Estados miembros tienen un «conjunto único de fuerzas» que pueden utilizar a nivel nacional o en marcos multilaterales. El desarrollo de las capacidades de los Estados miembros a través de la PCSD y el uso de instrumentos de la UE también ayudará a fortalecer las capacidades potencialmente disponibles para las Naciones Unidas y la OTAN.

${ }^{35}$ Consideración extraída del número monográfico editado por el Instituto Español de Estudios Estratégicos en Cuadernos de Estrategia 184, «Una estrategia global de la Unión Europea para tiempos difíciles» (2016) [acceso el 22 de junio de 2019, http://www.ieee.es/ Galerias/fichero/cuadernos/CE_184.pdf]. 
conflictos y las crisis exteriores» (Comisión Europea y Alta Representante de la UE, 2013). El «enfoque integral» de la UE o su «comprehensive approach» es un concepto que remite al tratamiento multidimensional propio de Naciones Unidas. Ambos organismos internacionales han desarrollado progresivamente en las últimas décadas un enfoque holístico como guía de su actividad en el ámbito de la seguridad, de forma particular en lo referente a la gestión de crisis y la resolución de $\operatorname{conflictos}^{36}$. En este contexto, el documento que acuna la EUGS ampara también los premisas políticas y legales que son vitales en el ADN de la UE y de sus Estados miembros, estos son: la paz y seguridad de los ciudadanos y del territorio de la UE; la prosperidad que implica un mercado interior sólido y un sistema internacional abierto; la democracia como valor fundamental a promover junto al respeto y promoción de los derechos humanos, libertades fundamentales y Estado de Derecho; y un orden mundial basado en normas y en el multilateralismo. Así mismo, en un repaso comparativo de ambas Estrategias, la EUGS otorga mayor énfasis a los intereses de la Unión en contraposición con el planteamiento previo más insistentes en los valores y principios. Este tratamiento no conlleva abandonar los principios y los valores tradicionales de la Unión, pues quedan implicados los intereses europeos: «nuestros intereses y nuestros valores van de la mano. Redunda en nuestro interés promover nuestros valores en el mundo. Al mismo tiempo, nuestros valores fundamentales están integrados en nuestros intereses» ${ }^{37}$.

Tras la tormenta inicial que generó el Brexit, se instauró una mínima calma entre los principales dirigentes políticos europeos, que propició un espíritu favorable a acoger esta Estrategia. Es por ello que confiaron la realización de un análisis más profundo de la EUGS a la Alta Representante. Dicho análisis dio comienzo con un debate en el Consejo de Asuntos Exteriores de 18 de julio de 2016, en el que los Ministros pusieron de manifiesto su disposición para seguir trabajando en la fase de aplicación ${ }^{38}$. Asimismo,

36 Vid. M. a Ángeles Alaminos, «Las estrategias de seguridad de la Unión Europea (2003, 2016): Contexto político, cambios esenciales y evolución de las prioridades políticas europeas relativas a África en materia de seguridad», Comillas Journal of International Relations, n. ${ }^{\circ}$ 13, (2018): 11-27, https://revistas.comillas.edu/index.php/internationalrelations/article/ download/10694/10087

37 Servicio Europeo de Acción Exterior (2016): 10.

${ }^{38}$ La Estrategia Global reapareció tanto en el discurso sobre el Estado de la Unión del presidente de la Comisión Europea, Jean-Claude Juncker, como en el posterior Consejo Europeo en Bratislava, en septiembre de 2016, donde se reiteró la necesidad de que la UE hable con una sola voz en el mundo y refuerce su seguridad y defensa con nuevas medidas que solventen los problemas que preocupan a los ciudadanos: combatir el terrorismo y la radicalización con mayor intercambio de información entre los Estados miembros, controlar la inmigración irregular con la aplicación del acuerdo UE-Turquía, mayor control de las fronteras exteriores y restaurar la libre circulación en el espacio Schengen. 
según se señala en las fichas temáticas proporcionadas por el Parlamento Europeo $^{39}$, para garantizar un sólido seguimiento de la aplicación de la Estrategia Global se determinó su revisión anual en cooperación con el Consejo, la Comisión y el Parlamento Europeo. Se añade que, junto con el repaso de las estrategias sectoriales existentes, se elaborarán y aplicarán nuevas estrategias temáticas y geográficas acordes con las prioridades políticas de la EUGS. Entre estas habrá una estrategia sectorial que defina el grado de ambición civil y militar de la Unión, las funciones, los requisitos y las prioridades de capacitación. Sirva como referencia que el 14 de noviembre de 2016, se presentó al Consejo de Asuntos Exteriores un Plan de aplicación de la PCSD, destinado a traducir en términos operacionales la visión que la EUGS define en lo concerniente a la seguridad y la defensa ${ }^{40}$. Dicho documento, elaborado por la Vicepresidenta y Alta Representante a partir de las diversas consultas mantenidas con los Estados miembros y las instituciones pertinentes, fue bien recibido por el Consejo. El Plan de aplicación define tres conjuntos de prioridades a las que puede contribuir cada misión de la PCSD, al hilo de las preferencias estratégicas de la EUGS: (a) responder a los conflictos y crisis exteriores; (b) desarrollar las capacidades de los socios; (c) proteger a la Unión y a sus ciudadanos. Y con el fin de aplicar solventemente la Estrategia Global, el Plan formula trece propuestas, entre ellas, una revisión anual coordinada del gasto en defensa, una mejor respuesta rápida de la Unión recurriendo a las agrupaciones tácticas, y una nueva cooperación única, estructurada y permanente para aquellos Estados miembros que deseen reforzar su colaboración militar (véase en este mismo trabajo el planteamiento que al respecto ofrece la cooperación estructurada permanente o PESCO).

Desde entonces, la Unión ha intensificado significativamente sus esfuerzos en el ámbito de la seguridad y la defensa. Al mismo tiempo, se reforzó su cooperación con la OTAN partiendo de la declaración conjunta sobre cooperación UE-OTAN firmada por el presidente del Consejo Europeo, el presidente de la Comisión Europea y el secretario general de la OTAN el 8 de julio de 2016, en paralelo a la Cumbre de Varsovia ${ }^{41}$. Otro

${ }^{39}$ Las fichas temáticas sobre la Unión Europea, elaboradas por los Departamentos Temáticos y la Unidad de Apoyo a la Gobernanza Económica del Parlamento Europeo, están disponibles en https://www.europarl.europa.eu/factsheets/es/home

${ }^{40}$ Los Ministros de Asuntos Exteriores celebraron una sesión conjunta con los ministros de Defensa sobre el plan de aplicación en materia de seguridad y defensa concebido en el marco de la Estratega Global de la UE [Brussels, 14 November 2016 (OR. en) 14392/16] Texto disponible en http://www.consilium.europa.eu/media/22460/eugs-implementationplan-st14392en16.pdf, acceso el 10 de septiembre de 2019.

${ }^{41}$ Véase las conclusiones y el conjunto común de propuestas en http://data.consilium.europa.eu/doc/document/ST-15283-2016-INIT/es/pdf, acceso el 8 de septiembre de 2019. 
reflejo de esta tendencia por vigorizar la autonomía estratégica de la Unión son las Conclusiones del Consejo de 6 de marzo de 2017, 18 de mayo de 2017 y 13 de noviembre de 2017. En las mismas se anotaron los avances y se ofrecieron orientaciones; y el 28 de mayo de 2018 se enunciaron en las Conclusiones del Consejo las medidas sobre refuerzo de la política común de seguridad y defensa civil ${ }^{42}$. De las diversas declaraciones anotadas se extrae un denominador común, esto es, un sistema global más incierto y menos estable, y el cuestionamiento del orden internacional. Para estabilizar y pacificar este entorno no solamente hace falta voluntad política común sino también el adecuado marco regulatorio, pues defendemos que las reglas jurídicas no son un obstáculo sino una garantía para que los ciudadanos se sientan libres y seguros. De ahí que Europa deba defender los derechos y libertades no solamente con reglas políticas y operativas sino también desde el Derecho, y asegurar que puede proteger a los ciudadanos de los riesgos existentes y de las amenazas emergentes. En este sentido, se apunta además lo decisivo que son los mecanismos de cooperación y diálogo y como a través de la EUGS se puede ganar cierta efectividad y credibilidad, siendo la UE, a su vez, fuerza motriz para la diplomacia, la cooperación y el compromiso que guían la evolución de la EUGS. Por tanto, ¿se convertirá hoy día esta Estrategia Global en la más adecuada brújula para encauzar la acción de la Unión y apuntalar su sana ambición de autonomía estratégica?

A pesar de la trama desafiante en la que se encuentra inserta la comunidad internacional y, por ende, Europa, la EUGS ha protagonizado un período de desarrollo y progreso en muchos frentes, pasando a la acción y no quedándose en un mero propósito de visión común, tal y como trasciende de los diversos Informes que reportan la implementación y evolución de esta Estrategia ${ }^{43}$. Por citar algunas de sus iniciativas se enuncian las siguientes: preservar un acuerdo internacional sobre el programa nuclear de Irán; re-activar la perspectiva europea para los Balcanes Occidentales; reforzar con los socios la gobernanza global y perseguir mutuamente soluciones beneficiosas para cuestiones comunes (lucha contra el cambio climático

${ }^{42}$ La Misión de la Unión Europea por el Estado de Derecho en Kosovo (EULEX) es la misión civil más amplia que se ha emprendido en el marco de la política europea de seguridad y defensa.

${ }^{43}$ El 14 de junio de 2019 se presentó por la Alta Representante Federica Mogherini el tercer Informe de aplicación de la EUGS (https://eeas.europa.eu/topics/eu-global-strategy/64160/eu-global-strategy-compass-our-action-difficult-times_en); el segundo Informe se anunció el 25 de junio de 2018 (https://eeas.europa.eu/topics/eu-global-strategy/47277/euglobal-strategy-report-year-2-year-action-address-predictable-unpredictability_en); y el primer Informe se emitió el 10 de enero de 2017 (https://eeas.europa.eu/sites/eeas/files/full_brochure_year_1_0.pdf). 
o la inmigración ilegal). En todo caso es el trabajo paciente de construir o invertir en «win-win solutions» ${ }^{44}$.

La EUGS alimenta la ambición de una autonomía estratégica para la UE al establecer como objetivo una estructura militar autónoma de la UE, que podría actuar independientemente de la OTAN. En este sentido, «como europeos, debemos asumir una mayor responsabilidad en nuestra seguridad. Frente a las amenazas externas, debemos estar preparados y capacitados para ejercer disuasión, dar respuesta y protegernos. Un nivel adecuado de ambición y autonomía estratégica es importante para que Europa tenga la capacidad de fomentar la paz y garantizar la seguridad dentro y fuera de sus fronteras», según la declaración de principios contenida en la Estrategia Mogherini. Cuando se habla de autonomía estratégica hay que preguntarse qué tareas militares y en qué partes del mundo deben los europeos emprenderlas por sí mismos, y contar obviamente con una dotación presupuestaria acorde, mayores capacidades y cooperación, una estructura militar más unida, una sólida industria europea de defensa y, obviamente, voluntad política por parte de los Estados miembros. Una de las tareas principales de esas fuerzas armadas sería, según BISCOP, proteger «el estilo de vida europeo» en casa ${ }^{45}$. En la EUGS no solo se habla de la gestión de las crisis exteriores sino también de que «los europeos deben ser capaces de proteger a Europa» y que «la UE debe ser capaz de contribuir a la protección de sus miembros, a petición de estos, y de sus instituciones».

En todo caso, aunque la Estrategia Global creó los instrumentos necesarios y colocó la planificación de las relaciones exteriores dentro de un mismo marco de valores, para aspirar a una verdadera autonomía estratégica y poner en marcha este nivel de actuación se necesita generar las condiciones necesarias. En efecto, un trabajo más cooperativo entre los Estados miembros en lo que respecta a temáticas relacionadas con la seguridad y la defensa, un Cuartel General Europeo, un mayor auge de la PESCO (o de la cooperación estructurada permanente) y del Fondo Europeo de Defensa, regulados de manera implícita o explícita en el Tratado de Lisboa. Se añade a este entramado, para aprovechar mejor las sinergias de la industria militar, la Agencia Europea de Defensa (creada en 2004), con el fin de promover una cooperación institucionalizada entre los Estados miembros a nivel europeo ${ }^{46}$, facilitar las

${ }^{44}$ El entrecomillado es nuestro, y alude a soluciones mutuamente beneficiosas para las partes.

45 Sven Biscop, «All or nothing? The EU Global Strategy and defence policy after the Brexit», Contemporary Security Policy, 37:3 (2016): 431-445.

${ }^{46} \mathrm{Su}$ objetivo era aprovechar las sinergias en la industria militar de los Estados participantes, facilitar las economías de escala y evitar duplicidades productivas y descoordinación de las inversiones públicas y privadas en la industria militar, en una UE que actualmente mantiene 37 tipos de tanques, 12 clases de aviones cisterna y 19 aviones de combate diferentes. 
economías de escala y evitar las duplicidades productivas y la descoordinación de las inversiones públicas y privadas en la industria militar ${ }^{47}$. Es lo que ni más ni menos vuelve a perseguir el Plan de Acción Europeo de Defensa junto con el Fondo Europeo, que pretende impulsar la innovación y la investigación en la industria de defensa para que sea más competitiva e internacional. Este impulso es, efectivamente, concluyente, pues solo así será capaz la Unión de expresar sus intereses en áreas que atañen a la PESC (derechos humanos, desarrollo, clima, comercio...), y mostrarse como un actor internacional legítimo, autónomo, seguro de sí mismo y creíble.

\section{Cobertura legal de la Acción Exterior Europea y de la Estrategia Global}

\section{Multilateralismo y Derecho Internacional Público}

La UE es firme defensora de un orden mundial sustentado en normas que ampare el respeto y promoción de los derechos humanos, las libertades fundamentales y el Estado de Derecho (artículo 21.1 del TUE), que con un multilateralismo apoyado en el Derecho Internacional se muestra como engranaje para la paz y la seguridad en Europa y en el resto del mundo ${ }^{48}$. Precisamente, el antecedente de la actual EUGS hacía hincapié en «un orden internacional basado en un multilateralismo eficaz», respetando el Derecho internacional, actuando según «el marco fundamental para las relaciones internacionales» que es la Carta de las Naciones Unidas y haciendo uso de medios tanto militares como civiles, incluyendo «la labor diplomática y las políticas de desarrollo, comercio y medio ambiente» (Consejo Europeo 2003), y diferenciándose de aquellas otras estrategias que ponen el «énfasis en el uso de medios coercitivos e instrumentos militares de forma unilateral, subordinando los enfoques multilaterales y el Derecho internacional a cuestiones de seguridad nacional y de integridad territorial $»^{49}$. Considerar que el multilateralismo no debe ser una formulación estática, sino que tiene

47 S. Besch, La Seguridad del suministro en la Defensa de la UE (2016).

48 Desde el fin de la Segunda Guerra Mundial, el multilateralismo ha representado la forma a través de la cual los Estados han hecho frente a amenazas contra la paz y seguridad internacionales, centrando sus acciones en lo prescrito por el Consejo de Seguridad (CS) y la Carta de la Organización de las Naciones Unidas (ONU). El multilateralismo puede darse de muchas formas: puede ser informal o institucionalizado.

49 Rafael Biermann, «NATO's Institutional Decline in Post-Cold War Security Governance», en C. Wagnsson, J. A. Sperling, \& J. Hallenberg (Eds.), European Security Governance: The European Union in a Westphalian World. London, (United Kingdom: Routledge, 2009): 55 . 
que adaptarse necesariamente a las notables e incesantes transformaciones globales, al convulso y dinámico contexto internacional y a las demandas de una sociedad civil internacional más organizada y activa en asuntos globales $^{50}$. Es por ello que en el devenir de la comunidad internacional se detecte el surgimiento de episodios de crisis del multilateralismo por su incapacidad de adaptarse y afrontar con solvencia los evites que surgen en materia de seguridad y la diversidad de puntos de vista.

Al posicionarse la Unión como actor clave en el orden multilateral basado en normas, tiene una buena oportunidad para gestionar y armonizar la pluralidad y complejidad de normas globales. A este respecto, «el Grupo de Trabajo UE 2020 debería hacer un esfuerzo especial para aunar los compromisos de la UE con respecto a la diversidad de puntos de vista y normas, y su gestión, por una parte, y el orden internacional basado en normas, por otra. Además, para ganarse el respeto como potencia capaz de gestionar la diversidad normativa, la UE debería introducir una explicación más directa y detallada de su enfoque de pragmatismo de principios para conciliar los valores y el interés propio» ${ }^{51}$.

Por su parte, la Acción Exterior Europea, conectándose las distintas facetas de su política (diplomacia, seguridad, comercio, desarrollo, ayuda humanitaria, negociaciones internacionales, etc.), promoverá, a través de su regulación, valores e intereses en favor de la paz, el desarrollo sostenible, la solidaridad, el respeto mutuo entre los pueblos, el comercio libre y justo, la erradicación de la pobreza y la protección de los derechos humanos y el respeto a los principios de la Carta de las Naciones Unidas (de acuerdo con lo enunciado en el artículo 3.5 del TUE). En efecto, en materia de paz y seguridad internacionales subordina el sistema de la Unión al más alto rango jurídico y político de la Carta de las Naciones Unidas. No olvidemos que la paz no es solamente un valor que deba regir las relaciones internacionales, sino que también es un derecho humano. Acogemos, siguiendo el sentir de la ONU, que la paz es un concepto amplio y positivo que engloba, entre otros derechos, el derecho a la seguridad humana y a vivir, el derecho a la resistencia contra la opresión de los regímenes que violan los derechos humanos, el derecho a la justicia, a la verdad y a la reparación efectiva que asiste a las víctimas de violaciones de los derechos humanos, etc.

50 Vid. Daniel García San José, «Unilateralismo y multilateralismo como conceptos de geometría variable en la sociedad internacional poscontemporánea», [acceso el 18 de julio de 2019, https://dialnet.unirioja.es/descarga/articulo/2800707.pdf].

51 Maryna Rabinovych y Zuzana Reptova, «The future of values in the EU Global Strategy 2020», ARI 112/2019:6 [acceso el 2 de enero de 2020, http://www.realinstitutoelcano. org/wps/portal/rielcano_en/contenido?WCM_GLOBAL_CONTEXT=/elcano/elcano_in/zonas_in/ari112-2019-rabinovych-reptova-the-future-of-values-in-the-eu-global-strategy-2020]. 
Gracias al Tratado de Lisboa (2009), Europa se expresa con más claridad en sus relaciones exteriores en virtud de la legitimidad que le da el reconocimiento legal de su personalidad jurídica (artículo 47 del TUE), la vigencia de un ordenamiento jurídico propio distinto del Derecho Internacional y la dotación de una estructura institucional, otorgándole la venía para celebrar acuerdos internacionales y participar en organizaciones internacionales (regionales y mundiales), hablando y actuando como una única entidad (artículo 21.1 del TUE). Consecuentemente, la UE activa y mantiene asociaciones con los principales actores de la escena mundial, incluidos los grupos regionales y las potencias emergentes (entre sus socios estratégicos reseñar los Estados Unidos, Japón, Canadá, Rusia, la India y China). Y para cumplir solventemente con estos objetivos, la UE dispone de ciertos fondos e instrumentos financieros que gestionan la ayuda a la cooperación, equivalente a 96.768 millones de euros para el período 2014-202052. Para hacer valer las consideraciones anteriores bajo el prisma de la EUGS, es pertinente atestiguar que la legítima presencia de la UE en contextos de riesgo se justifica no solo por su voluntad de ser un actor global, con un espíritu volcado hacia la prevención de conflictos y el mantenimiento de la paz y seguridad internacional, como señalan los artículos 2 y 21 del TUE, sino también por el marco regulatorio que da cobertura a estos principios y que se describe a continuación.

\section{Fundamentos y marco normativo de la Acción Exterior Europea}

Con el TUE termina de consolidarse el original modelo adoptado por el sistema europeo para determinar las modalidades y el alcance de su intervención en el complejo entramado de las relaciones internacionales y de su Acción Exterior, situándonos en presencia de un ámbito de actuación europeo, atribuido implícita o explícitamente por los Estados miembros a las instituciones, apoyada operativamente en aquella reconocida personalidad jurídica y sin alcance global o universal en cuanto a su contenido, que coincide sectorialmente con otras políticas europeas, por importantes que éstas

52 Para conocer más sobre los fondos de la Acción Exterior de la UE, los instrumentos para el período 2014-2020, las facilidades de inversión, los métodos de ejecución de la financiación véase el documento editado por Secretaría de Estado para la Unión Europea (Ministerio de Asuntos Exteriores y de Cooperación) en 2015 bajo el título «La Acción Exterior de la Unión Europea 2014-2020. Guía práctica de su financiación», disponible en [acceso el 15 de septiembre de 2019 http://www.exteriores.gob.es/Portal/es/SalaDePrensa/Multimedia/Documents/GUIA\%20PRACTICA\%20FINANCIACION.pdf]. 
$\operatorname{sean}^{53}$. El estudio de los contenidos nucleares que alimentan las dos Estrategias europeas citadas en este análisis nos permite observar un cambio de rumbo y una redefinición de la PESC tanto desde sus presupuestos normativos como desde las nuevas aproximaciones más centradas en los objetivos e intereses propios de Europa, superándose el marco del poder blando ${ }^{54}$.

Sigue intacto el compromiso de la Unión con el desarrollo de una sociedad internacional fuerte y de un orden internacional basado en el derecho, donde las instituciones internacionales funcionen adecuadamente, tal y como se matiza en la EUGS. Se inspira fervientemente en las premisas legales reguladas en el Derecho originario o primario (Tratados y principios generales del Derecho) y derivado de la Unión (Reglamentos, Directivas, Decisiones...), que sustentan la Acción Exterior y sus diversos ejemplos prácticos, fundamentalmente la PESC y la PCSD. El punto de partida del marco regulatorio en el Derecho originario europeo lo encontramos en las disposiciones generales relativas a la Acción Exterior, artículos 21 y 22, Capítulo I del Título V del TUE que son aplicables también al ámbito PESC en virtud del artículo 23 TUE. En el Tratado de Funcionamiento de la Unión Europea (TFUE), la Acción Exterior de la Unión se regula en la quinta parte, artículos 205 a 222; también se aplican los artículos 346 y 347 de la séptima parte. Por su parte, la base jurídica propia de la PESC, que se creó en 1993 en virtud del Tratado de Maastricht, se encuentra en el TUE, según la versión revisada de Lisboa (dentro de la Sección 1. del Capítulo 2, Título V del TUE [arts. 23 a 41]).

Precisar que al examinar el ámbito de la Acción Exterior de la Unión es necesario realizar una distinción de partida consagrada en el nuevo Tratado de la Unión Europea, es la separación que en los Tratados (Tratado de

53 Sobre este concepto existe una amplia literatura, aunque el lector español puede remitirse al análisis crítico del mismo elaborado entre nosotros por Antonio Remiro Brotons [«Las relaciones exteriores de las Comunidades Europeas», en la obra colectiva dirigida por E. García de Enterría, J.D. González Campos y S. Múñoz Machado, Tratado de Derecho comunitario europeo. Estudio sistemático desde el derecho español, Vol. III (Madrid, 1986): 637 y ss.]

${ }^{54}$ «El profesor de la Harvard's Kennedy School of Government, Joseph Nye, lo cristaliza en el concepto de «poder blando» (soft power) para reflejar la potencialidad de la proyección cultural en la influencia en la opinión pública de otros países como forma de condicionar así, desde adentro, la acción de los gobiernos extranjeros. La diversificación de las herramientas de influencia exterior blanda ha hecho que a la alta cultura la acompañen hoy la cultura popular, la educación, la ciencia o la comunicación exterior (medios transnacionales, redes sociales y otras formas de presencia en los entornos digitales) en una tarea identificable más adecuadamente con el término de «diplomacia pública» para incorporar la diversificación de ámbitos y actores, y la transformación horizontal de los modelos de una influencia exterior más dialógica, colaborativa e inclusiva» (Ángel Badillo, «Poder blando, influencia exterior y diplomacia cultural», The Diplomat, 6 de diciembre de 2016, https://thediplomatinspain.com/2016/12/poder-blando-influencia-exterior-y-diplomacia-cultural/). 
la Unión Europea y Tratado de Funcionamiento de la Unión Europea) se efectúa entre los aspectos económicos del proceso de integración y el resto de los ámbitos incluidos en la política exterior. Mientras que las relaciones económicas exteriores (política comercial, celebración de acuerdos internacionales, relación con otras Organizaciones Internacionales, la adopción de medidas restrictivas o sanciones...) quedan bajo la égida competencial de la Unión, el resto de ámbitos, esto es, los que conforman la PESC se mantienen y permanecen bajo la lógica gubernamental siendo, por el momento, competencia de los Estados.

Por constituir uno de los pilares intergubernamentales de la UE, la PESC ocupa un lugar destacado en el ordenamiento jurídico europeo, elevándose a uno de los rangos esenciales de la Unión, pero quedando excluida la adopción de actos legislativos. Consagrándose en el Tratado de la UE como objetivo de la Unión el «afirmar su identidad en el ámbito internacional, en particular mediante la realización de una política exterior y de seguridad común que incluya, en el futuro, la definición de una política de defensa común que podría conducir en su momento, a una defensa común». La característica principal de la PESC ha sido y sigue siendo su naturaleza intergubernamental, donde rige la regla de la unanimidad, por lo que el aspecto clave de los procesos de toma de decisiones reside en la voluntad política de los Estados miembros, según sus intereses nacionales a la hora de actuar o no actuar, y su concepción del uso de la fuerza y de la intervención externa. En función de esta premisa básica, el consenso de los Estados miembros, lograr la unanimidad, es un factor limitante que condiciona la posición y la actuación de la Unión en materia PESC, las iniciativas en relación con los temas globales más importantes y el establecimiento de mecanismos o instrumentos para avanzar (o no) en este sentido. Recordándose el respeto por la identidad nacional de sus Estados miembros, y ese delicado equilibro que la Unión debe sostener entre lo supranacional y lo nacional impacta en ese enfoque integral y holístico que se persigue asentar en este ámbito. Ejercicio que no es tarea fácil y que muchas veces condena el óptimo avance del propio proceso de integración pues, en ciertos casos, priman los intereses particulares de los socios frente a una postura común europea. Al respecto, está siempre candente en el debate político-jurídico, si este modelo de PESC responde a una verdadera voluntad unitaria en la que se yuxtaponen las voces individuales, o si es el resultado práctico dimanante de la necesidad de reafirmar un mínimo mecanismo de cooperación intergubernamental que alumbre una posición común.

Suprimida la estructura de pilares, tras la entrada en vigor del Tratado de Lisboa en 2009 deberán diferenciarse conceptualmente las relaciones exteriores de la PESC. Interrelación que es a un mismo tiempo funcional, orgánica (por la plena asociación de la Comisión al Consejo para garantizar la 
coherencia y realización de la Acción Exterior de la Unión), presupuestaria y física (centralización de las actividades en Bruselas y no en el país que ejerce la Presidencia del Consejo). Por consiguiente, ambos conceptos y las actividades derivadas no deben ser analizados como compartimentos estancos. Al respecto, coincidimos completamente con las tesis que subrayan la amplia y sutil interrelación entre ambas ${ }^{55}$. En efecto, no son ámbitos incomunicados. Y para darle vida práctica el Tratado de Lisboa sostiene jurídicamente la creación de toda una gama de nuevos agentes de la PESC, entre ellos, las figuras de Presidente «permanente» del Consejo Europeo y del Alto representante de la Unión para Asuntos Exteriores y Política de Seguridad (que también ejerce de Vicepresidente de la Comisión). Ambos roles velan por la coherencia de la actuación exterior de la Unión. De este modo, la UE puede ejercer una labor más sólida y eficaz a nivel internacional. Desde el punto de vista institucional, el impacto de las actuaciones de la Unión también queda reforzado gracias al Servicio de Acción Exterior, que presta su ayuda al Alto Representante recurriendo a los medios de que disponen las instituciones y los Estados miembros (artículo 27 del TUE), y a la actualización de la PCSD como parte integral de la PESC.

Resultado de la propia evolución, uno de los objetivos principales de la Conferencia intergubernamental que condujo a la firma del proyecto del Tratado de Amsterdam (1997) era reformar la PESC, con el fin de perfeccionar su funcionamiento y equipar mejor a la Unión en el ámbito internacional. Tal como describió Shaun Riordan, la firma del Tratado de Saint Malo en 1998 entre el Primer Ministro británico Tony Blair y el Presidente francés Jacques Chirac, pudo ser la oportunidad perdida de reforzar la defensa europea y diseñar una verdadera PESC ${ }^{56}$. El tratamiento legal de esta política se ha ido reforzando progresivamente en el acervo comunitario. Estas disposiciones, además de dotar de mayor coherencia y unidad a la Acción Exterior de la UE, determinan sus principios orientadores ${ }^{57}$; definen

55 Es la posición mantenida entre nosotros por Antonio Remiro Brotons, Breve diccionario del Tratado de la Unión Europea (Madrid: Centro Español de Relaciones Internacionales, 1993): 206-207, para quien las relaciones exteriores de la Comunidad terminan donde comienza la política exterior y de seguridad común, acciones interrelacionadas que examinamos ahora.

56 Shaun Riordan, «Brexit: Implicaciones para la seguridad europea», Documento de Opinión, 63bis/2016 (Instituto Español de Estudios Estratégicos, 2016), acceso el 26 de julio de 2019, http://www.ieee.es/Galerias/fichero/docs_opinion/2016/DIEEEO63bis-2016_Brexit_Implicaciones_Riordan.pdf

57 «La acción de la Unión en la escena internacional se basará en los principios que han inspirado su creación, desarrollo y ampliación y que pretende fomentar en el resto del mundo: la democracia, el Estado de Derecho, la universalidad e indivisibilidad de los derechos humanos y de las libertades fundamentales, el respeto de la dignidad humana, los principios de igualdad y solidaridad y el respeto de los principios de la Carta de las Naciones Unidas y del Derecho internacional» (artículo 21.1.1 TUE). 
los objetivos de las políticas comunes y acciones ${ }^{58}$; prevén la posibilidad de tejer relaciones, asociaciones con los terceros países y con las organizaciones internacionales (regionales o mundiales) que compartan los principios mencionados; y establece la regulación desde el punto de vista procedimental e institucional otorgándole un claro protagonismo al Consejo Europeo (institución encargada de definir los intereses y objetivos estratégicos de toda la Acción Exterior y sus decisiones). En cuanto a las obligaciones, se prevén en el artículo 24.3 del TUE una serie de obligaciones generales dirigidas a todos los Estados miembros en este ámbito. Conforme a este planteamiento legal, la Unión dirigirá, definirá y ejecutará la PESC basada en el desarrollo de la solidaridad política mutua de los Estados miembros, en la identificación de los asuntos que presenten un interés general y en la consecución de una convergencia cada vez mayor de la actuación de los Estados miembros (artículo 24.2 del TUE).

Las disposiciones específicas de la PESC determinan sus reglas y procedimientos que se extienden a las obligaciones generales, objetivos y principios asumidos por los Estados ${ }^{59}$. Los principios se concretan en el apoyo activo y sin reservas a esta política, en el de lealtad y solidaridad mutua, así como en el de abstención de acciones contrarias a los intereses y cohesión de la Unión en el contexto de las relaciones internacionales globales. Sin duda, una muestra del perfil amplio del sistema PESC que cubre la diplomacia y los temas relacionados con seguridad y defensa (PCSD), pero también las políticas comunes de naturaleza exterior como el comercio, la cooperación internacional y desarrollo, la

58 Los objetivos de las políticas comunes y acciones de la Unión Europea en materia exterior son enumerados en el artículo 21.2 TUE. Estos son, a) defender sus valores, intereses fundamentales, seguridad, independencia e integridad; b) consolidar y respaldar la democracia, el Estado de Derecho, los derechos humanos y los principios del Derecho internacional; c) mantener la paz, prevenir los conflictos y fortalecer la seguridad internacional, conforme a los propósitos y principios de la Carta de las Naciones Unidas, así como a los principios del Acta Final de Helsinki y a los objetivos de la Carta de París, incluidos los relacionados con las fronteras exteriores; d) apoyar el desarrollo sostenible en los planos económico, social y medioambiental de los países en desarrollo, con el objetivo fundamental de erradicar la pobreza; e) fomentar la integración de todos los países en la economía mundial, entre otras cosas mediante la supresión progresiva de los obstáculos al comercio internacional; f) contribuir a elaborar medidas internacionales de protección y mejora de la calidad del medio ambiente y de la gestión sostenible de los recursos naturales mundiales, para lograr el desarrollo sostenible; g) ayudar a las poblaciones, países y regiones que se enfrenten a catástrofes naturales o de origen humano; y h) promover un sistema internacional basado en una cooperación multilateral sólida y en una buena gobernanza mundial.

59 Para conocer el panorama histórico y los progresos aportados por el TUE y por el Tratado de Ámsterdam véase el siguiente informe http://eur-lex.europa.eu/legal-content/ES/ TXT/?uri=LEGISSUM\%3Aa19000, acceso el 2 de septiembre de 2019. 
ayuda humanitaria, la ampliación, y la vecindad. Además, deben incluirse también los importantes aspectos internacionales de muchas otras políticas sectoriales como, por ejemplo, migración, industria, economía, finanzas, digitalización, energía, clima, medio ambiente, agricultura, pesca, justicia, etc. Asimismo, la PESC se aborda también en el artículo 2 de las disposiciones comunes que prevé que uno de los objetivos de la Unión es el anhelado ideal de defensa común. A lo anterior debe añadirse lo establecido en el artículo 26.1 del TUE donde se prevé que el Consejo Europeo defina puntualmente los intereses estratégicos, los objetivos y las orientaciones generales de la PESC y, por extensión, también de la Acción Exterior en su conjunto (artículos 21 y 22 TUE). En el trámite de definición y aplicación de la PESC, el Consejo Europeo y el Consejo deberán pronunciarse por unanimidad excepto si los Tratados disponen otra consideración. Mientras que su ejecución es asumida por el Alto Representante de la Unión y por los Estados miembros, de conformidad con los Tratados (artículo 24.1 del TUE). En cuanto al control de legalidad, el Tribunal de Justicia de la Unión Europea no tiene atribuida competencia respecto de estas disposiciones, con la salvedad de su competencia para tutelar el respeto del artículo 40 del TUE y la legalidad de determinadas decisiones contempladas en el párrafo segundo del artículo 275 del TFUE.

En el marco de la PESC se posiciona la PCSD. Ahora que la UE está inmersa en una crisis existencial o de identidad, la política de defensa ha avanzado a velocidad de crucero desde 2016, pasando del inter-gubernamentalismo a la cooperación. El embrión de la PCSD se sitúa con la entrada en vigor del Tratado de Ámsterdam (1997), resucitando la cooperación militar, y su posterior desarrollo en el Tratado de Lisboa, reconociéndola como parte integrante de la PESC (Sección 2. ${ }^{\circ}$ del Capítulo 2, Título V del TUE, artículos 42 a 46), así como en los Protocolos números 1,10 y 11 y en las Declaraciones 13 y 14. La Unión dirige la PCSD (artículo 25 TUE) definiendo sus orientaciones generales, adoptando decisiones (incorpora la distinción entre estrategias comunes, posiciones comunes y acciones comunes) y compartiendo sus objetivos con los de la PESC para ofrecer a la Unión una capacidad operativa basada en medios civiles y militares. De ahí que, para su plena puesta en práctica, los países miembros deban facilitar a la Unión sus capacidades civiles y militares.

El Tratado de Ámsterdam se esfuerza por superar las contradicciones existentes entre los objetivos comunes de la PESC, destacados por su ambición, y los medios de los que la Unión se ha dotado para alcanzarlos, que no parecen estar a la altura de aquéllos y de los retos que emergen. Este Tratado decretó un proceso de decisión más eficaz que incorporaba la abstención constructiva y las votaciones por mayoría cualificada. 
Por su parte, en el Tratado de Niza (2003) se introdujeron otros cambios para racionalizar el proceso de toma de decisiones y se encargó al Comité Político y de Seguridad, establecido por una Decisión del Consejo en enero de 2001, que ejerciera el control político y la dirección estratégica de las operaciones de gestión de crisis. En el proceso de toma de decisiones, intervienen el Consejo Europeo y el Consejo de la Unión Europea (artículo 42 del TUE), aplicándose la regla de la unanimidad, con algunas destacadas excepciones relativas a la Agencia Europea de Defensa (artículo 45 del TUE) y a la cooperación estructurada permanente (artículo 46 del TUE), que se someten a la regla de la votación por mayoría. Normalmente, es el Alto Representante de la Unión, que también actúa como Vicepresidente de la Comisión Europea, quien elabora las propuestas de decisiones. Y en el Tratado de Lisboa se introduce el concepto de una política europea de capacidades y de armamento (artículo 42, apartado 3, del TUE), si bien su definición sigue pendiente. Asimismo, se establece un vínculo entre la PCSD y otras políticas de la Unión al requerir que la Agencia Europea de Defensa y la Comisión se mantengan en contacto en caso necesario (artículo 45, apartado 2, del TUE). Esto afecta en especial a las políticas de la Unión en materia de investigación, industria y espacio, en las que el Parlamento europeo está ahora facultado para desempeñar un papel mucho más importante que antes por lo que respecta a la PCSD.

Por su parte, la aplicación de la agenda estratégica y el logro de los resultados asociados a la misma exigen la adopción de medidas legislativas. A pesar del sistema político que representa la UE y de las muchas dificultades adicionales que lleva aparejado, se ha conseguido cumplir los compromisos asumidos en 2014, contenidos en la agenda 2014-2019. Para el verano de 2018, la Comisión Juncker había presentado todas las propuestas legislativas a las que se había comprometido al inicio de su mandato ${ }^{60}$. De este modo, la UE fue capaz de cumplir su agenda estratégica en tiempo y forma gracias al compromiso de la Comisión Juncker con una mejor legislación desde el primer momento. Un ejemplo, entre otros, del cumplimento alcanzado para guiar la respuesta de la UE a un entorno de seguridad complejo y de rápida evolución fue la adopción por la Comisión de la Agenda Europea de Seguridad tras los terribles ataques terroristas de 2015 en París. Al respecto, el Presidente Juncker garantizó un planteamiento coherente, eficiente y transversal en virtud del nombramiento de un comisario encargado de la Unión de la Seguridad, facultado para coordinar el trabajo rela-

${ }^{60}$ En total, la Comisión Juncker ha presentado 471 nuevas propuestas legislativas y ha asumido la tramitación de otras 44 propuestas presentadas por Comisiones anteriores. 
cionado con la seguridad en todos los ámbitos de actividad con el apoyo de un grupo de trabajo específico formado por expertos de todos los servicios de la Comisión pertinentes ${ }^{61}$.

En este recorrido, las instituciones europeas amparadas por el marco regulatorio prosiguen su trabajo para eliminar en sus políticas de relaciones exteriores, seguridad y defensa los déficits acumulados (retrasos en la puesta en marcha de medidas, falta de consenso entre los países miembros, intereses divergentes, diferencias en la evaluación de los riesgos...), auspiciar superávits en favor de la mejor convergencia y autonomía estratégica y el logro de un acuerdo en lo que respecta a instrumentos jurídicos, toma de decisiones y estructuras militares comunes. En esta línea de trabajo, reseñar que la Comisión Europea no tiene un mandato para la política militar y de defensa. La base legal para sus actividades relacionadas con el Fondo Europeo de Defensa no son los contenidos del TFUE asociados con la política exterior y de seguridad, sino más bien los artículos 173 y 182 de dicho Tratado, que se relacionan con las actividades económicas, específicamente para mejorar la innovación industrial y competencia.

De forma particular, la EUGS no sitúa en un plano prioritario el enfoque normativo de la Unión y su trasfondo idealista, exhibido en la implementación de sus principios y valores, para manifestar claramente la preponderancia de sus intereses, en términos de estabilidad y de seguridad como ejes preferentes de la Acción Exterior europea. Los intereses europeos son, por tanto, los factores clave a la hora de contribuir al desarrollo de la gobernanza global y de las organizaciones regionales e internacionales. La creciente aspiración de la Unión Europea de erigirse en un actor internacional creíble y con capacidad de respuesta, donde los valores estén respaldados por instrumentos y medidas concretas en seguridad y defensa, reflejan el reconocimiento de las limitaciones del enfoque normativo de la Unión, como se explicita en la Estrategia de 2016.

\section{IV. Últimos avances en el desarrollo de la autonomía estratégica}

De las directrices generales o básicas que son de obligado cumplimiento y que se extraen del marco normativo citado se alude a diversas he-

61 Vid. Comunicación de la Comisión al Parlamento Europeo, al Consejo Europeo, al Consejo, Al Comité Económico y Social Europeo y al Comité de las Regiones [COM (2019) 218 final, Bruselas, 30 de abril de 2019]: Europa en mayo de 2019: preparación para una Unión más unida, más fuerte y más democrática en un mundo sumido en una incertidumbre creciente. Contribución de la Comisión Europea a la reunión informal de los dirigentes de la EU-27 en Sibiu (Rumanía) el 9 de mayo de 2019, https://ec.europa.eu/transparency/regdoc/ rep/1/2019/ES/COM-2019-218-F1-ES-MAIN-PART-1.PDF 
rramientas legales que contribuyen operativamente al logro de cierta autonomía estratégica y proyectan las virtudes de la EUGS. Destacamos para nuestro estudio, la cláusula de asistencia mutua y la cooperación estructurada permanente (PESCO), junto con aquellas otras herramientas que contribuyen a impulsar la ambición de autonomía estratégica para la Unión, señalándose sus últimos avances.

\section{Cláusula de asistencia mutua}

La cláusula de asistencia mutua es la clave de bóveda de la alianza defensiva europea. Dicha cláusula se considera una importante innovación del Tratado de Lisboa. Su regulación prevista en el artículo 42.7 del Tratado de Lisboa sería «equivalente al artículo 5 del Tratado de Washington de la Alianza Atlántica ${ }^{62}$ porque es una alianza defensiva que surge ante la necesidad de establecer un mecanismo que garantice la seguridad en los países europeos» ${ }^{63}$. El texto completo de la cláusula de asistencia mutua del TUE dispone que «si un Estado miembro es objeto de una agresión armada en su territorio, los demás Estados miembros le deberán ayuda y asistencia con todos los medios a su alcance, de conformidad con el artículo 51 de la Carta de las Naciones Unidas. Ello se entiende sin perjuicio del carácter específico de la política de seguridad y defensa de determinados Estados miembros. Los compromisos y la cooperación en este ámbito seguirán ajustándose a las obligaciones adquiridas en el marco de la Organización del Tratado del Atlántico Norte, que seguirá siendo, para los Estados miembros que forman parte de la misma, el fundamento de su defensa colectiva y el organismo de ejecución de esta». No se ha definido ningún procedimiento formal y el precepto aludido no explicita que la ayuda deba ser militar, lo que permite la participación de países neutrales como Austria, Finlandia, Irlanda y Suecia. Comparándose ambas regulaciones, para algunos autores se trata de «una alianza defensiva o mecanismo que garantiza la seguridad en los países europeos», que obliga a la ayuda y asistencia por parte de todos los Estados Miembros, pero de ma-

${ }^{62}$ El texto artículo V del Tratado de Bruselas modificado de 1954: «En el caso de que una de las Altas Partes Contratantes fuere objeto de una agresión armada en Europa, las otras, de conformidad con lo dispuesto en el artículo 51 de la Carta de las Naciones Unidas, le prestarán ayuda y asistencia por todos los medios a su alcance, tanto militares como de otra índole».

${ }^{63}$ Francisco Aldecoa, «Una política de defensa europea compatible con la Alianza Atlántica; en UE-EEUU: Una relación indispensable para la paz y la estabilidad mundiales», Cuaderno de Estrategia, n. 177 (noviembre 2015), http://www.ieee.es/publicaciones-new/ cuadernos-de-estrategia/2015/Cuaderno_177.html 
nera asimétrica. Así, los países neutrales no se excederán del umbral de la mera solidaridad política, y para quienes son también miembros de la OTAN, la cooperación se ajusta a compromisos adquiridos dentro de la Alianza.

La primera vez que se activó esta cláusula fue en Francia tras los atentados del Daesh en París el 13 de noviembre de 2015. El Gobierno francés la invocó, demandando apoyo militar fuera de su territorio y por eso no evocó la cláusula de solidaridad que tiene una óptica de protección civil (artículo 222 del Tratado de Funcionamiento de la UE). En virtud de esta asistencia mutua, los Estados miembros prestarán ayuda con todos los medios a su alcance, en caso de una agresión armada de manera bilateral y asimétrica. Una vez alegada la cláusula de asistencia mutua, si un Estado miembro necesita apoyo militar en el exterior, tiene que precisar qué necesita y dónde, y la ayuda se le prestaría de manera bilateral y por la UE. La debilidad que se muestra es que no existen mecanismos reglados que indiquen cómo debe prestarse esa ayuda lo cual dificulta su ejecución ${ }^{64}$. El Parlamento Europeo pidió mediante resolución a la Alta Representante que corrigiese la falta de claridad de la cláusula de defensa mutua recogida en el artículo 42.7 del TUE ${ }^{65}$, y que definiese las directrices y modalidades de aplicación de dicha cláusula para que los Estados miembros puedan responder de forma eficaz cuando se invoque. La misma adolece de un desarrollo regulatorio propio en cuanto a su aplicación, aunque sí incluye un acuerdo para implementarla en caso de ciberataques. En primera instancia, la paz y la seguridad de los ciudadanos europeos y de su territorio implica tener la capacidad de actuación para hacer frente a los compromisos de asistencia mutua y solidaridad de los Tratados europeos. Es por ello que esta cláusula convive con otra regulada en el Tratado de Lisboa, se trata de la cláusula de solidaridad mutua (artículo 222 TFUE), que se introdujo en la forma de una declaración adoptada en las conclusiones del Consejo Europeo de los días 25 y 26 de marzo de 2004 a raíz del atentado terrorista perpetrado en Madrid. En todo caso, se deben realizar avances firmes para cooperar de manera más decidida y compartida en el ámbito de la seguridad y de la defensa.

64 Vid. Miguel Ángel Benedicto Solsona, «Pasos de gigante en la defensa europea», Política Exterior, vol. 31, n. ${ }^{\circ} 175$ (enero-febrero 2017):106-115.

65 Pide a la AR/VP que corrija la falta de claridad de la cláusula de defensa mutua recogida en el artículo 42, apartado 7, del TUE, y que defina las directrices y modalidades de aplicación de dicha cláusula para que los Estados miembros puedan responder de forma eficaz cuando se invoque. 


\section{Cooperación Estructurada Permanente}

Ante la transformación del entorno de seguridad, la Estrategia Global infunde sobre la PESC un proceso de intensificación de la cooperación. Los Estados miembros convinieron en impulsar la labor común en esta materia y reconocieron que, para lograr este objetivo, era preciso mejorar la coordinación e incrementar las inversiones en defensa y la cooperación en cuanto al desarrollo de sus capacidades. Con el fin de poder desarrollar capacidades y su despliegue común, se contempla la posibilidad de que varios Estados miembros de la UE colaboren más estrechamente en el ámbito de la seguridad y la defensa dando lugar a la cooperación estructurada permanente (PESCO), tal y como se regula en los artículos 42.6 y 46 y en el Protocolo 10 del Tratado de la UE. Al marco normativo originario se añade que el 11 de diciembre de 2017, el Consejo adoptó la Decisión (PESC) 2017/2315, por la que se establece una cooperación estructurada permanente y se fija la lista de los Estados miembros participantes. Es una iniciativa que faculta a un grupo de Estados miembros a coordinar sus objetivos en el ámbito de la seguridad, las adquisiciones de material bélico y las futuras operaciones conjuntas de defensa y de paz, que inviertan en proyectos compartidos y mejoren la contribución y la disponibilidad operativa de sus fuerzas armadas. La diferencia entre la PESCO y otras formas de cooperación es el carácter jurídicamente vinculante de los compromisos contraídos por los Estados miembros participantes.

Para poder establecer la PESCO los países interesados debían cumplir previamente dos condiciones: (a) desarrollar de manera intensiva capacidades de defensa que permitan el desarrollo de contribuciones nacionales y la participación en fuerzas multinacionales, en los principales programas europeos de equipos militares y en la actividad de la Agencia Europea de Defensa; (b) y tener la capacidad, a más tardar en 2010, de aportar unidades de combate y apoyo logístico para las tareas mencionadas en el artículo 43 del TUE en un plazo de 5 a 30 días en caso de necesidad, para un período de 30 a 120 días. Más de veinte países de la UE anunciaron su interés por participar en la $\mathrm{PESCO}^{66}$. El acta sobre la creación de la coalición fue firmada por

${ }^{66}$ Los veinticinco Estados miembros que participan en la cooperación estructurada permanente son: Alemania, Austria, Bélgica, Bulgaria, Chipre, Croacia, Eslovaquia, Eslovenia, España, Estonia, Finlandia, Francia, Grecia, Hungría, Irlanda, Italia, Letonia, Lituania, Luxemburgo, los Países Bajos, Polonia, Portugal, la República Checa, Rumanía y Suecia. El 13 de noviembre de 2017, los ministros de veintitrés Estados miembros firmaron una notificación conjunta sobre la cooperación estructurada permanente y se la entregaron a la Alta Representante y al Consejo. El 7 de diciembre de 2017, Irlanda y Portugal notificaron también su decisión de participar en la cooperación estructurada permanente. 
todos los países de la UE excepto por Reino Unido, Dinamarca, Malta, Portugal, Austria e Irlanda ${ }^{67}$, estando la toma de decisiones en manos de esos Estados en el seno del Consejo. Este planteamiento se entiende sin perjuicio del carácter específico de la política de seguridad y defensa de determinados Estados miembros de la UE.

Gracias a esta modalidad de cooperación, los países miembros aumentan su eficacia al hacer frente a los retos de seguridad y avanzar hacia una mayor integración y fortalecimiento de la cooperación en materia de defensa en el marco de la UE. Pero ¿qué beneficios afronta los países miembros con este tipo de acción cooperativa? Pues solicitar el establecimiento entre sí de un marco institucionalizado; asumir compromisos a nivel de inversión en proyectos compartidos; mejorar la contribución y la disponibilidad operativa de sus fuerzas armadas ${ }^{68}$; así como la creación de un instrumento para financiar esas capacidades como es el Fondo Europeo de Defensa ${ }^{69}$. Esto es, permite a los Estados que cumplan con determinados criterios de capacidades militares, que puedan solicitar el establecimiento entre sí de un marco institucionalizado y regular la coordinación de aquéllas, y de toda su industria militar, en el seno de la Unión. De este modo se reforzará la capacidad de la UE como interlocutor mundial en materia de seguridad, lo que contribuirá a proteger a los ciudadanos de la UE y a maximizar la eficacia del gasto en defensa. En las conclusiones del Consejo del 14 de noviembre de 2016, los Estados miembros reconocieron que era necesario «profundizar la cooperación en materia de defensa y garantizar un uso más óptimo, incluida

${ }^{67}$ Los Estados miembros que participan en la cooperación estructurada permanente también han adoptado una declaración simultáneamente a la adopción de la Decisión por la que se establece la cooperación estructurada permanente. La declaración acoge con satisfacción el acuerdo político por el que se define una lista inicial de diecisiete proyectos que se llevarán a cabo en el marco de la cooperación estructurada permanente. Los proyectos abarcan ámbitos como la formación, el desarrollo de capacidades y la disponibilidad operativa en materia de defensa. Se prevé que el Consejo adopte formalmente estos primeros proyectos a principios de 2018.

${ }^{68}$ Notification on permanent structured cooperation (PESCO) to the Council and to the High Representative of the Union for foreign affairs and security policy. Texto disponible en: https://www.consilium.europa.eu/media/31511/171113-pesco-notification.pdf, acceso el 18 de junio de 2019.

${ }^{69}$ El Fondo Europeo de Defensa debe llegar a ser un factor clave para el futuro de la defensa europea. El Fondo respaldará el nivel de ambición que la Unión acuerde al considerar los diferentes escenarios hacia una Unión de Seguridad y Defensa Europea, presentados en el documento de reflexión sobre el futuro de la defensa europea [Véase el documento de reflexión sobre el futuro de la defensa europea, $\operatorname{COM}(2017)$ 315]. Asimismo, la «communication from the Commission to the European Parliament, the Council, The European Economic and Social Committee of the regions. Launching the European Defence Fund $[\mathrm{COM}(2017)$ 295 final]» expone las herramientas para promover la adquisición conjunta de capacidades de defensa por los Estados miembros. Otras medidas se adoptarán en fases ulteriores del establecimiento del Fondo. 
la coherencia, de los planes de gasto de defensa». Para la revisión periódica de esos compromisos, dentro de la EUGS se formuló la «sincronización gradual y adaptación mutua de los ciclos de planificación de defensa nacional y las prácticas de desarrollo de capacidades». Así, la revisión anual coordinada sobre defensa anunciada a finales de 2016 fue el mecanismo diseñado para cumplir con estos objetivos y debe estar basado en una mayor transparencia, visibilidad política y compromiso de los Estados miembros.

La PESCO tenía que haberse puesto en marcha en 2010 pero no fue hasta el Consejo Europeo de diciembre de 2017, cuando se activó con la participación de veinticinco Estados miembros, salvo Malta, Dinamarca y Reino Unido. En marzo de 2018, se iniciaron los primeros 17 proyectos dentro de la PESCO (la lucha frente a ciberataques o un Centro de Mando Médico, por citar algunos). La secuencia de los compromisos más vinculantes asumidos por los Estados miembros que participan en la PESCO se establecía a partir de principios de julio de 2018, según una recomendación del Consejo. Una lista actualizada de proyectos PESCO y sus participantes fue prevista para noviembre de 2018, aprobándose una segunda tanda con 17 nuevos proyectos ${ }^{70}$. Las condiciones generales para la participación de Estados terceros en proyectos PESCO se presentarán según lo previsto en una decisión del Consejo ${ }^{71}$. Los proyectos abarcan ámbitos como la formación, el desarrollo de capacidades y la disponibilidad operativa en tierra, mar y aire, así como en materia de ciberdefensa. Se definirán en consonancia con las prioridades en materia de defensa acordadas por los Estados miembros en el marco de la PESC y, en particular, en el contexto del Plan de Desarrollo de Capacidades (PDC), si bien podrán también tenerse en cuenta las prioridades regionales e internacionales, como las relacionadas con la OTAN. En todo caso, los proyectos desarrollados en el contexto de la PESCO garantizan una mayor cooperación entre los diferentes Estados miembros de forma continua.

Junto a lo anterior, el Consejo adoptó en junio de 2018 un conjunto común de reglas de gobernanza para los proyectos ejecutados en el marco de la PESCO, siguiendo lo dispuesto en el artículo 4, apartado 2, letra f), de la

70 Cooperación en materia de defensa: el Consejo emprende 17 nuevos proyectos de CEP. Al respecto véase el siguiente documento https://www.consilium.europa.eu/es/press/ press-releases/2018/11/19/defence-cooperation-council-launches-17-new-pesco-projects/, acceso el 15 de julio de 2019. Un resumen de los primeros proyectos colaborativos PESCO está accesible en el siguiente documento emitido por el Consejo de la Unión Europea http://www. consilium.europa.eu/media/32079/pesco-overview-of-first-collaborative-of-projects-forpress.pdf, acceso el 20 de julio de 2019.

${ }_{71}$ Un resumen de los proyectos de colaboración de la CEP se encontrará en el siguiente cuadro https://www.consilium.europa.eu/media/39384/table-pesco-projects.pdf, acceso el 15 de julio de 2019 . 
Decisión (PESC) 2017/2315, para que los Estados miembros participantes en un proyecto individual puedan adaptarse, si es necesario, a ese proyecto. Según lo especificado en el considerando 5 de la Decisión (PESC) 2018/340 del Consejo ${ }^{72}$, a fin de garantizar la coherencia, la ejecución de todos los proyectos de la PESCO se basará en el conjunto de reglas de gobernanza comunes para proyectos, que incluyen, entre otras, normas sobre el cometido de los observadores, si procede. Se añade la Decisión del Consejo 9660/18 por la que se establece un conjunto de reglas de gobernanza comunes para proyectos de la cooperación estructurada permanente ${ }^{73}$. Dicho conjunto debe proporcionar un marco que garantice una aplicación coherente y sistemática de los proyectos de la PESCO e incluir mecanismos para informar periódicamente al Consejo sobre el desarrollo de cada uno de los proyectos, de conformidad con el artículo 5, apartado 3, de la Decisión (PESC) 2017/2315, y para permitir la necesaria supervisión por parte del Consejo. A este respecto, habría que concretar aún más las funciones y responsabilidades de los Estados miembros participantes, incluidas, entre otras, las funciones de los Estados observadores, en su caso, y de la secretaría de la PESCO, gestionada conjuntamente por el Servicio Europeo de Acción Exterior, incluido el Estado Mayor de la UE y la Agencia Europea de Defensa.

Para garantizar la adecuada aplicación de la PESCO, se subraya la tendencia que se da entre los Estados participantes de incrementar el nivel de los presupuestos de defensa y de las inversiones conjuntas en defensa. Reseñar que los presupuestos agregados de defensa aumentaron un 3,3\% en 2018 y un 4,6 \% en 2019. Otra buena predisposición es que los Estados miembros participantes utilizan cada vez más, en la planificación nacional en materia de defensa, los medios, iniciativas e instrumentos de la UE. En efecto, va ganando relevancia esta fórmula cooperativa con el desarrollo de nuevas herramientas para la seguridad y defensa europea.

\section{Otras herramientas}

Tras la aprobación de la EUGS, además de ponerse en marcha los instrumentos legales que recogía el Tratado de Lisboa, la UE ha desarrollado nuevas herramientas que permiten vislumbrar una mayor autonomía estratégica. Entre ellas, el Fondo Europeo de Defensa, que es explícitamente

72 Decisión (PESC) 2018/340 del Consejo, de 6 de marzo de 2018, por la que se establece la lista de proyectos que deben desarrollarse en el marco de la Cooperación Estructurada Permanente (CEP) (DO L 65 de 8.3.2018, p. 24).

73 Documento disponible en http://data.consilium.europa.eu/doc/document/ST-96602018-INIT/es/pdf, acceso el 15 de julio de 2019. 
geopolítico, para impulsar una mayor cooperación en la industria europea y el mercado único de la defensa, recogido en la propuesta de la Comisión Europea sobre el Plan de Acción Europeo de Defensa ${ }^{74}$; y un Fondo Europeo de Paz, fuera del presupuesto comunitario, para financiar los costos comunes de las misiones militares de la UE y contribuir a la financiación de operaciones militares de apoyo a la paz.

Asimismo, se ha reforzado el despliegue de misiones civiles y de gestión de crisis, tal y como recoge el Pacto sobre la Vertiente Civil ${ }^{75}$ de la PCSD; y se ha puesto en marcha la Revisión Anual Coordinada de la Defensa (CARD, en sus siglas en inglés) para el intercambio de información y cooperación entre los Estados miembros en el desarrollo de capacidades militares, y se ha creado una Capacidad Militar de Planificación y Ejecución para mejorar las estructuras de gestión de crisis dentro del Plan de Aplicación en el ámbito de la seguridad y la defensa ${ }^{76}$. Además; se ha incrementado la cooperación entre la UE y la OTAN que actualmente aplican 74 medidas concretas en conjunto ${ }^{77}$.

\section{Consideraciones finales}

El examen de los elementos centrales de las dos Estrategias comentadas nos permite observar que la reorientación progresiva de la Acción Exterior y de sus políticas es una vía para afianzar la posición mundial de la UE como «global player», pero además sería conveniente el fomento de su capacidad normativa y que incluya la definición gradual de una política que desemboque en una verdadera defensa común. Los acontecimientos geopolíticos contemporáneos y los pasos dados por los Estados miembros en los últimos dos años ${ }^{78}$, encaminan a la UE hacia una Europa de la Defensa. En efecto, los líderes europeos afirman el deseo de llegar al mismo sitio, una visión compartida y una acción común, pero ninguno parece saber con cer-

74 Véase el comunicado de prensa de la Comisión Europea, Plan de Acción Europeo de Defensa: hacia un Fondo Europeo de Defensa, disponible en http://europa.eu/rapid/press-release_IP-16-4088_es.htm.

${ }^{75}$ Council Conclusions on strengthening civilian CSDP - Council Conclusions (28 May 2018) https://www.consilium.europa.eu/media/35380/st09288-en18.pdf

76 Véase Plan de aplicación en el ámbito de la seguridad y la defensa - Factsheet. Documento disponible en https://eeas.europa.eu/headquarters/headquarters-homepage/40839/plande-aplicaci\%C3\%B3n-en-el-\%C3\%A1mbito-de-la-seguridad-y-la-defensa-factsheet_es.

77 Joint declaration on EU-NATO cooperation, 10 de julio de 2018. Documento disponible en https://www.consilium.europa.eu/media/36096/nato_eu_final_eng.pdf.

${ }^{78}$ Los Estados miembros ya han comenzado a aumentar sus presupuestos en defensa para llegar al objetivo del $2 \%$ de la OTAN. 
teza cuál es la hoja de ruta a seguir. Si bien, teniendo como telón de fondo la EUGS y el afán de autonomía estratégica, es imprescindible que la UE se posicione como actor independiente con sus misiones PCSD y compatible con la alianza que representa la OTAN. Esta compatibilidad o complementariedad tiene su razón de ser, más aún, por el contexto geopolítico internacional que incide sobre manera en el desarrollo de un entorno de seguridad multilateral, más si cabe por la diversificación de las amenazas ${ }^{79}$, que se extienden cada vez más fuertemente, están interconectadas y a una escala global, desdibujándose la frontera entre la seguridad interna y la externa.

Respaldado por el anhelo de un mayor grado de autonomía estratégica, la EUGS germina una visión e inversión colectiva integrada en tres parámetros (credibilidad, capacidad de respuesta e integración). Y es por ello que estimamos que esta Estrategia sólo podrá ser reforzada si se dispone de medios creíbles (legales, políticos, operativos e industriales) y con capacidad de reacción que le permitan intervenir en las crisis que pongan en juego la paz y la seguridad mundial. Para ello, debe respetarse lo regulado en el ordenamiento jurídico, desarrollarse mecanismos de financiación y cooperación multilateral, asentarse una voluntad política común, y flexibilizarse el uso de los grupos de combate para poder integrar módulos de competencias (ciberguerra, fuerzas especiales, personal médico) en una operación en curso. En este entorno, la Acción Exterior y la PESC siguen su camino a un buen ritmo. En efecto, a partir del planteamiento de la EUGS y del marco regulatorio de la Acción Exterior esbozado en los Tratados se está progresando hacia una mayor autonomía estratégica. En este sentido, los últimos dos años han sido decisivos para avanzar en virtud de las políticas y acciones concretas citadas en este trabajo. La Estrategia Global ha promovido una mayor coherencia en la Acción Exterior de la UE y la primera prioridad de la EUGS ha sido la seguridad. Con los instrumentos ya reseñados en este artículo, la Unión Europea de Seguridad y Defensa ha dado sus primeros pasos. Las misiones internacionales tienen mejores estructuras de mando y se ha invertido más en capacidades civiles. Los Estados miembros invierten en proyectos industriales y de investigación comunes, para desarrollar las capacidades de defensa que necesita la UE y la cooperación con distintos socios (desde la ONU a la Alianza Atlántica) es cada vez mayor. Como resumió la Alta Representante Mogherini «nuestros socios saben que la fuerza de Europa no es solo nuestro poder blando ${ }^{80}$.

79 Estos riesgos de seguridad no son solo de naturaleza tradicionalmente militar, sino que incluyen ataques cibernéticos, piratería y amenazas al sector energético y al medio ambiente, entre otros.

${ }^{80}$ The European Union's Global Strategy. Three years on, looking forward (2019). Documento disponible en https://eeas.europa.eu/sites/eeas/files/eu_global_strategy_2019.pdf 
Pero aflora una problemática y es la debilidad que atraviesan los Gobiernos nacionales y sobre todo el eje franco-alemán. Mientras tanto, las divisiones Norte-Sur (por el desajuste económico) y Este-Oeste (por el problema migratorio), no parecen que vayan a desaparecer a corto plazo. Consecuentemente, Europa vive una crisis existencial que requiere, entre otras cosas y según lo apuntado anteriormente, un salto cualitativo hacia una política de seguridad y defensa más europea. Esto es, construir más y mejor integración y una capacidad de respuesta común para afrontar con garantías desafíos imposibles de abordar desde la dimensión puramente nacional. Asimismo, le falta también a la UE credibilidad, coherencia interna y un ángulo de integración que le permita definir objetivos más claros en el ámbito de la seguridad y de la defensa. Sin duda, la influencia de las políticas domésticas, como la de los países implicados o afectados por situaciones críticas (por ejemplo, la crisis de los refugiados), repercuten no positivamente, pues se ha generado una menor sintonía con la aspiración integradora europea al percibirse distintas intensidades e intereses contrapuestos.

Conforme a este planteamiento, el Derecho europeo es vital y/o mediador. ¿Por qué? Porque el ordenamiento jurídico tiene una misión reguladora y organizativa tendente a garantizar, entre otros, la paz y la seguridad como valores jurídicamente perseguibles. Esto es, permitir la realización legítima de los objetivos recogidos en los Tratados y demás normativa. Del mismo modo, precisamos que los Estados miembros de la Unión deben estar firmemente convencidos de la necesidad de actuar como un grupo cohesionado. Una cultura de seguridad y defensa común es posible a pesar de las diferentes percepciones de amenaza y solo con una clara y compartida determinación de avanzar en la PESC, se podrá mejorar, erradicando los defectos y cubriendo las carencias.

\section{Bibliografía}

Aldecoa, Francisco. «La cooperación estructurada permanente: haciendo creíble la Alianza Defensiva de la Unión Europea, sin perder la condición de potencia normativa y diplomática», Anuario Español de Derecho Internacional, n. ${ }^{\circ} 34$ (2018): 1003-1020.

Arteaga, Félix, Jermalavicius, Tomás; Marrone, Alessandro; Maulny, Jean-Pierre y Terlokowski, Marcin. "Appropiate level of European Strategic Autonomy», Ares Group Reports, n. ${ }^{\circ} 8$ (November 2016), acceso el 15 de junio de 2019, https://www.iris-france.org/wp-content/uploads/2016/11/ARES-Group-ReportStrategic-autonomy-November-2016.pdf

Bailes, A. J. K. The European Security Strategy: An Evolutionary History. SIPRI Policy Paper, 2005. 
Barbé, Esther (dir.). La Unión Europea en las relaciones internacionales. Madrid: Tecnos, 2014.

Cameron, Fraser. An Introduction to European Foreign Policy. London: Routledge, 2012.

Cebada Romero, Alicia. «La peculiaridad de la Acción Exterior de la Unión Europea», Remiro Brotons, Antonio y Blázquez Navarro, Irene (coords.). El futuro de la Acción Exterior de la Unión Europea. Tirant lo Blanch, 2006: 73-100.

Centro Superior de Estudios de la Defensa Nacional. «La cooperación estructurada permanente en el marco de la Unión Europea», Documentos de Seguridad y Defensa, n. ${ }^{\circ}$ 42, Mayo 2011.

Comisión de Asuntos Exteriores, Informe sobre la Unión en un entorno mundial en mutación: un mundo más conectado, disputado y complejo (2015/2272(INI)), 29 de marzo de 2016, acceso el 15 de julio de 2019, http://www.europarl.europa.eu/doceo/document/A-8-2016-0069_ES.pdf

Cooperación Estructurada Permanente (CEP). Profundizar la cooperación entre los Estados miembros de la UE en materia de defensa, Noviembre 2018, acceso el 10 de julio de 2019, https://eeas.europa.eu/sites/eeas/files/pesco_factsheet_november_2018_es_0.pdf

De Carlos Izquierdo, Javier. «La nueva Estrategia de Seguridad Europea 2016», Documento Marco, n. ${ }^{\circ}$ 16, Instituto Español de Estudios Estratégicos, 30 de septiembre 2016.

Declaración de Roma, 25 de marzo de 2017, Declaración de los dirigentes de veintisiete Estados miembros y del Consejo Europeo, el Parlamento Europeo y la Comisión Europea, acceso el 5 de junio de 2019, https://europa.eu/europeanunion/file/22720/download_es?token=9W6X2tk6

García Cantalapiedra, David y Barras, Raquel. «El Norte de África y el Sahel y la Estrategia Global de Seguridad de la Unión Europea», UNISCI Journal, n. ${ }^{\circ} 42$, 2016: 173-196.

Howorth, Jolyon. «Autonomy and Strategy: what should Europe want?», Security Policy Brief, n. ${ }^{\circ} 110$, April 2019, acceso el 20 de julio de 2019, http://www.egmontinstitute.be/content/uploads/2019/04/SPB110.pdf?type=pdf

Libro Blanco sobre el futuro de Europa, 2017, acceso el 4 de junio de 2019, https:// ec.europa.eu/commission/sites/beta-political/files/libro_blanco_sobre_el_futuro_de_europa_es.pdf

Mangas Martín, Araceli. Tratado de la Unión Europea, Tratado de Funcionamiento y otros actos básicos de la Unión Europea. Madrid: Tecnos, 2018.

Moller, Bjorn. European Security. The role of regional organisations. London: Routledge, 2016.

Proyecto Europa 2030. Retos y oportunidades, Informe al Consejo Europeo del Grupo de Reflexión sobre el futuro de la UE en 2030, acceso el 15 de julio de 2019, https://www.consilium.europa.eu/media/30761/qc3210249esc.pdf

Rabinovych, Maryna y Reptova, Zuzana: «The future of values in the EU Global Strategy 2020», ARI 112, 19 de noviembre, acceso el 2 de enero de 2020, http:// Www.realinstitutoelcano.org/wps/portal/rielcano_en/contenido?WCM_GLOBAL_CONTEXT=/elcano/elcano_in/zonas_in/ari112-2019-rabinovych-reptova-the-future-of-values-in-the-eu-global-strategy-2020. 
Sanahuja, José Antonio: «La Estrategia Global y de Seguridad de la Unión Europea: narrativas securitarias, legitimidad e identidad de un actor en crisis», WP01/18, Instituto Complutense de Estudios Internacionales, acceso el 20 de junio de 2019, https://eprints.ucm.es/46196/1/WP\%2001-18.pdf

Serrano, Pedro. «The bundle of sticks: a stronger European defense to face global challenges», Working Paper, n. ${ }^{\circ}$ 03/2019, Real Instituto Elcano.

Servicio Europeo de Acción Exterior. Una visión común, una actuación conjunta: una Europa más fuerte. Estrategia global para la política exterior y de seguridad de la Unión Europea, 2016, acceso el 10 de julio de 2019, http://eeas.europa.eu/ archives/docs/top_stories/pdf/eugs_es_.pdf

Techa, Jan. «The EU's New Global Strategy: Useful or Pointless?», Carnegie Europe, 20 octubre 2016, acceso el 15 de julio de 2019, https://carnegieeurope.eu/ strategiceurope $/$ ?fa $=63994$

Tocci, Nathalie. Framing the EU Global Strategy. A stronger Europe in a fragile world. Basingstoke: Palgrave-MacMillan, 2017.

Unión Europea. From Shared Vision to Common Action: A Global Strategy for the European Union's Foreign and Security Policy Implementation Report Year 2, June 2018, acceso el 5 de junio de 2019, https://eeas.europa.eu/sites/eeas/files/ eugs_annual_report_year_2.pdf

Varga, Gergely. «Towards European Strategic Autonomy? Evaluating the New CSDP Initiatives », KKI Studies, T-2017/7, Institute for Foreign Affairs and Trade.

\section{Sobre la autora}

María José Molina García. Profesora acreditada contratada Doctora (ANECA). Responsable de Programas del Centro de Estudios Garrigues. Doctora en Ciencias Políticas y de la Administración. Licenciada en Ciencias Políticas y Sociología. Licenciada en Derecho. Anteriormente Directora del Departamento de Ciencias Jurídicas y Políticas de la Universidad Europea de Madrid. Ha sido colaboradora honorífica en el Departamento de Derecho Constitucional de la Universidad Complutense. Experiencia docente e investigadora en Centros universitarios públicos y privados (Centro de Estudios Garrigues, Universidad Europea, Universidad Complutense, Staffordshire University, Eserp Business School). Sus áreas de investigación son la política Exterior de la UE, el Derecho Europeo, Derecho Administrativo y Administración Pública, contando con diversas publicaciones y participación en Congresos y Seminarios nacionales e internacionales en esos ámbitos de estudio. Participación en Comités y otras representaciones (Summer Law School, Seminario Ítalo-Spagnolo - Red Europea de Investigación Jurídica, Premios Jóvenes Emprendedores Sociales - Universidad Europea, Premio The Young Excellence Challenge Centro de Estudios Garrigues...). Evaluadora externa en diversas Revistas 
(Comillas Journal of International Relations, Revista Universitaria Europea, y Anuario Jurídico Villanueva).

\section{About the author}

María José Molina García. PhD contract professor (ANECA). Head of Programmes at Centro de Estudios Garrigues. PhD in Political Science and and Administration. Degree in Political Science and Sociology. Degree in Law. Previously Director of the Department of Legal and Political Sciences at the Universidad Europea of Madrid. She has been an Honorary Collaborator of the Department of Constitutional Law at the Universidad Complutense. Teaching and research experience in public and private universities (Centro de Estudios Garrigues, Universidad Europea, Universidad Complutense, Staffordshire University, Eserp Business School). His areas of research are EU foreign policy, European Law, Administrative Law and Public Administration, with several publications and participation in national and international Congresses and Seminars in these fields of study. Participation in Committees and other representations (Summer Law School, Italo-Spanish Seminar European Legal Research Network, Young Social Entrepreneur Awards - Universidad Europea, The Young Excellence Challenge - Centro de Estudios Garrigues...). External evaluator in various Journals (Comillas Journal of International Relations, Revista Universitaria Europea, y Anuario Jurídico Villanueva).

\section{Sobre el autor}

Miguel Ángel Benedicto Solsona es Doctor en Ciencias Políticas y Sociología por la Universidad Complutense de Madrid (UCM), licenciado en Derecho por Universidad de Zaragoza, en Periodismo por la UCM y en Ciencias Políticas por la UNED. Es titulado Superior en La situación de seguridad en Irán: repercusión en el escenario regional y en el entorno mundial y en El conflicto árabe-israelí: nuevas expectativas por el Centro Superior de Estudios de la Defensa Nacional (CESEDEN) y Universidad Rey Juan Carlos. Actualmente es profesor adjunto de Relaciones Internacionales en la Universidad Europea, y profesor asociado de Relaciones Internacionales en la Facultad de Ciencias Políticas de la UCM, en la Universidad Pontificia de Comillas y en la Universidad Camilo José Cela. Sus áreas de investigación son la Seguridad y Defensa y política Exterior de la UE, la política de Comunicación de las instituciones europeas y la 
Diplomacia Pública. Entre sus últimos libros, ha sido coordinador junto a Eugenio Nasarre y Francisco Aldecoa de Europa como tarea (Marcial Pons, 2018); junto a Eugenio Hernández de Europa 3.0. 90 miradas desde España a la UE (Plaza y Valdés, 2014) y autor de Estados Unidos $3.0 \mathrm{La}$ Era Obama vista desde España (Plaza y Valdés e Instituto Franklin-UAH, 2012); La mayor operación de solidaridad de la historia. Crónica de la política regional de la UE en España (Oficina de Publicaciones Oficiales de la Comisión Europea, 2006 y 2. ${ }^{\text {a }}$ edición por Plaza y Valdés, 2007) y Europa a Debate. Veinte años después (1986-2006) (Plaza y Valdés en coedición con el Ministerio de Asuntos Exteriores, 2006). Es miembro del Board del Movimiento Europeo Internacional y copresidente del Itinerario Cultural Europeo Vía Carlomagno. Colabora como analista con La Noche en 24 Horas de Televisión Española, en el diario La Razón y en el Instituto Español de Estudios Estratégicos.

\section{About the author}

Miguel Ángel Benedicto Solsona is a PhD in Political Science and Sociology from the Complutense University of Madrid (UCM), a degree in Law from the University of Zaragoza, in Journalism from the UCM and in Political Science from the UNED. He is higher degree in The Security Situation in Iran: Impact on the Regional Scenario and in the Global Environment and in the Arab-Israeli Conflict: New Expectations by the Higher Center for National Defense Studies (CESEDEN) and Rey Juan Carlos University. He is currently an associate professor of International Relations at the European University, and associate professor of International Relations at the Faculty of Political Science of the UCM, at the Pontifical University of Comillas and at the Camilo José Cela University. His areas of research are the Security and Defense and Foreign Policy of the EU, the Communication policy of the European institutions and the Public Diplomacy. Among his latest books, he has been coordinator with Eugenio Nasarre and Francisco Aldecoa of Europa como tarea (Marcial Pons, 2018) with Eugenio Hernández of Europa 3.0. 90 miradas desde España a la UE (Plaza y Valdés, 2014) and author of Estados Unidos 3.0 La Era Obama vista desde España (Plaza y Valdés e Instituto Franklin-UAH, 2012); La mayor operación de solidaridad de la historia. Crónica de la política regional de la UE en España (Official Publications of the European Commission, 2006 and 2. ${ }^{\mathrm{a}}$ edition by Plaza y Valdés, 2007) y Europa a Debate. Veinte años después (1986-2006) (Plaza y Valdés in coedition with Foreign Affairs Ministry,2006). He is a member of the Board of the International European Movement and co- 
chair of the European Cultural Itinerary Via Carlomagno. He collaborates as an analyst with La Noche in 24 Horas of Spanish Public Television, in the newspaper La Razón and in the Spanish Institute of Strategic Studies at the Spanish Defense Ministry. 


\section{Derechos de autor}

Los derechos de autor (para la distribución, comunicación pública, reproducción e inclusión en bases de datos de indexación y repositorios institucionales) de esta publicación (Cuadernos Europeos de Deusto, CED) pertenecen a la editorial Universidad de Deusto. El acceso al contenido digital de cualquier número de Cuadernos Europeos de Deusto es gratuito inmediatamente después de su publicación. Los trabajos podrán leerse, descargarse, copiar y difundir en cualquier medio sin fines comerciales y según lo previsto por la ley; sin la previa autorización de la Editorial (Universidad de Deusto) o el autor. Así mismo, los trabajos editados en CED pueden ser publicados con posterioridad en otros medios o revistas, siempre que el autor indique con claridad y en la primera nota a pie de página que el trabajo se publicó por primera vez en CED, con indicación del número, año, páginas y DOI (si procede). Cualquier otro uso de su contenido en cualquier medio o formato, ahora conocido o desarrollado en el futuro, requiere el permiso previo por escrito del titular de los derechos de autor.

\section{Copyright}

Copyright (for distribution, public communication, reproduction and inclusion in indexation databases and institutional repositories) of this publication (Cuadernos Europeos de Deusto, CED) belongs to the publisher University of Deusto. Access to the digital content of any Issue of Cuadernos Europeos de Deusto is free upon its publication. The content can be read, downloaded, copied, and distributed freely in any medium only for non-commercial purposes and in accordance with any applicable copyright legislation, without prior permission from the copyright holder (University of Deusto) or the author. Thus, the content of CED can be subsequently published in other media or journals, as long as the author clearly indicates in the first footnote that the work was published in CED for the first time, indicating the Issue number, year, pages, and DOI (if applicable). Any other use of its content in any medium or format, now known or developed in the future, requires prior written permission of the copyright holder. 